\title{
Organic corrosion inhibitors: where are we now? A review. Part III. Passivation and the role of the chemical structure of organophosphates
}

\author{
Yu.I. Kuznetsov \\ A.N. Frumkin Institute of Physical Chemistry and Electrochemistry, Russian Academy of \\ Sciences, Leninskii pr. 31, Moscow, 119071 Russian Federation \\ E-mail: kuznetsov@ipc.rssi.ru
}

\begin{abstract}
This article continues the review of studies (2006-2016) dealing with the passivation of various metals by solutions of organic corrosion inhibitors. It provides an overview of papers on the passivating properties of organophosphates, their complexes and salts. The results of corrosion and electrochemical studies, as well as studies on the composition and structural features of surface layers on metals by a variety of physicochemical methods are considered.
\end{abstract}

Key words: metal corrosion, inhibitors, metal passivation, organophosphates.

Received: May 6, 2017. Published: June 14, 2017.

doi: $\underline{10.17675 / 2305-6894-2017-6-3-1}$

Organic phosphorus compounds are often called organophosphates, especially in the case of pesticides and even toxic agents. Of course, it is unlikely that such materials have application prospects for the inhibition of metal corrosion. That is why in this series of reviews we consider organophosphates in a narrower sense limited to phosphoric acid esters and their salts, as well as phosphonic acids, their salts or complex compounds with metal cations [1-4].

The easy synthesis of acid esters of phosphoric acid, the stability of mono- and disubstituted ester anions, their ability to form complexes and hydrophobic passive films on oxidized metal surfaces has been known for a long time [1]. They can be used for the passivation of phosphated metal surfaces, and their salts with amines are used within deicing formulations. These salts can inhibit not only corrosion but also formation of deposits, so they are used in two-phase systems in the oil industry. Since higher homologues are more effective, the solubility of alkylphosphonic acids is commonly increased by ethoxylation. Salts of these acids are used in cooling lubricants, e.g., waterbased cutting fluids. The low toxicity, ability to be chemisorbed on a metal surface, and some useful technological properties of acid esters of phosphoric acid continue to motivate researchers to look for effective corrosion inhibitors of various metals among these compounds and to study their protection mechanisms [5-14]. 
Of special interest among acidic phosphoric acid esters are phytic acid ( $\mathrm{PhA})$, also known as $D$-myo-inositol-1,2,3,4,5,6-hexakisdihydrophosphoric acid, its salts or complexes with various cations of metals [15]. The "myo" prefix indicates a particular orientation of the hydroxy groups with respect to the inositol ring, while the phosphate groups are not bound to each other. This acid is an ester of a hexabasic alcohol myoinositol and six phosphoric acid residues (Figure 1).

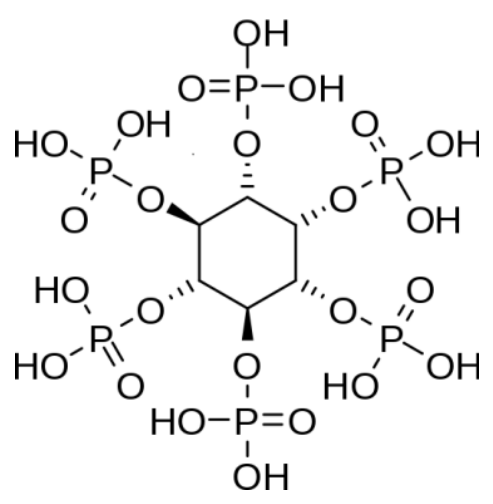

Figure 1. Phytic acid.

Due to its structure containing 12 acidic groups, $\mathrm{PhA}$ and its salts can form complexes with metal ions. The layers that they form on the surface protect the metal from corrosion.

According to [16], in early 1980s Japanese researchers drew attention to $\mathrm{PhA}$ as a non-toxic, environmentally friendly compound of plant origin used as a food additive. In view of this, it was planned to use $\mathrm{PhA}$ and its salts, e.g. $\mathrm{CaPhA}, \mathrm{MgPhA}$ and $\mathrm{NaPhA}$, to control pitting of copper pipes for domestic water. T. Notoya [17] found that the effect of $\mathrm{NaPhA}$ on copper dissolution in borate buffer solutions is strongly dependent on $\mathrm{pH}$. However, at $\mathrm{pH} 6.5$ copper dissolution accelerated at all $\mathrm{NaPhA}$ concentrations. In order to make the NaPhA efficiency increase with its concentration, the solution $\mathrm{pH}$ had to be increased to 9.2. It is no coincidence that later it was found to manifest protective properties toward steel in concrete pore liquid [18]. Moreover, its $\mathrm{Ca}$ and $\mathrm{Mg}$ salts were found to be more efficient than the acid itself or $\mathrm{NaPhA}$ in inhibiting the corrosion not only of $\mathrm{Cu}$ but also of brass [16]. In the past decade, studies on corrosion inhibitors based on $\mathrm{PhA}$, its salts and complexes were expanded and revealed interesting features of the mechanism of their protective action in relation not only to the above mentioned metals, but also galvanized steel [19], $\mathrm{Ag}$ [20], as well as $\mathrm{Mg}$ [21] and its alloys [22, 23].

\section{Organic esters of phosphoric acid}

Monoalkyl, dialkyl and diphenyl phosphates can be strongly adsorbed on various metals and their oxides. It is therefore not surprising that studies on the characteristics of their adsorption continued in the past decade. Thus, the ellipsometric in situ method, which we used for the first time to obtain the adsorption isotherm of sodium dialkyl phosphate on a 
passive electrode made of pure iron $(C<0.001 \%)$ from aqueous borate buffer solution with $\mathrm{pH} 7.4$ [5], received further application.

Sodium dioctyl phosphate (SDOP), which is one of the best passivators of mild steel in neutral solutions, has been studied most widely. Bis(2-ethylhexyl) phosphate (EHPh) that have a similar composition has long been known as an effective dispersant that can be used, for example, to stabilize so-called "magnetic ink". In view of this, its adsorption from tetrahydrofuran (THF) solution on fine magnetic metallic iron pigments consisting predominantly of iron $(69.7-72.3 \% \mathrm{Fe}, 14.9-17.7 \% \mathrm{O}, 1.9-4.15 \% \mathrm{Al})$ was studied in [24]. The isotherm obtained for EHPh was of Langmuir type, from which the monolayer capacity was calculated $\left(Q_{\mathrm{m}}=110 \mu \mathrm{mol} / \mathrm{g}\right)$ and the area available for its molecule was assessed as $82-87 \AA^{2}$. This value is close to the theoretically calculated molecule area, i.e., $74 \AA^{2}$, so the authors concluded that an EHPh monolayer on the pigment surface has a dense packing. However, neither the Fourier IR nor XPS analysis of pigment surface with EHPh adsorbed on it confirmed the possibility of metal-phosphate binding such as, for example, in iron phosphate. In view of this, comprehensive studies carried out on low carbon steel in aqueous solutions containing SDOP are noteworthy. Note that according to [5], it has better passivating properties in neutral aqueous solution than its branched homologue, EHPh.

As one can see from the anodic polarization curves shown in Figure 2, SDOP causes spontaneous passivation of mild steel at relatively low concentrations and increases the local depassivation potential, $E_{\mathrm{pit}}$. Since the protective layers formed by SDOP on the metal surface are obviously of self-assembling type, their protective properties should depend on the duration of an electrode exposure to the inhibitor solution.

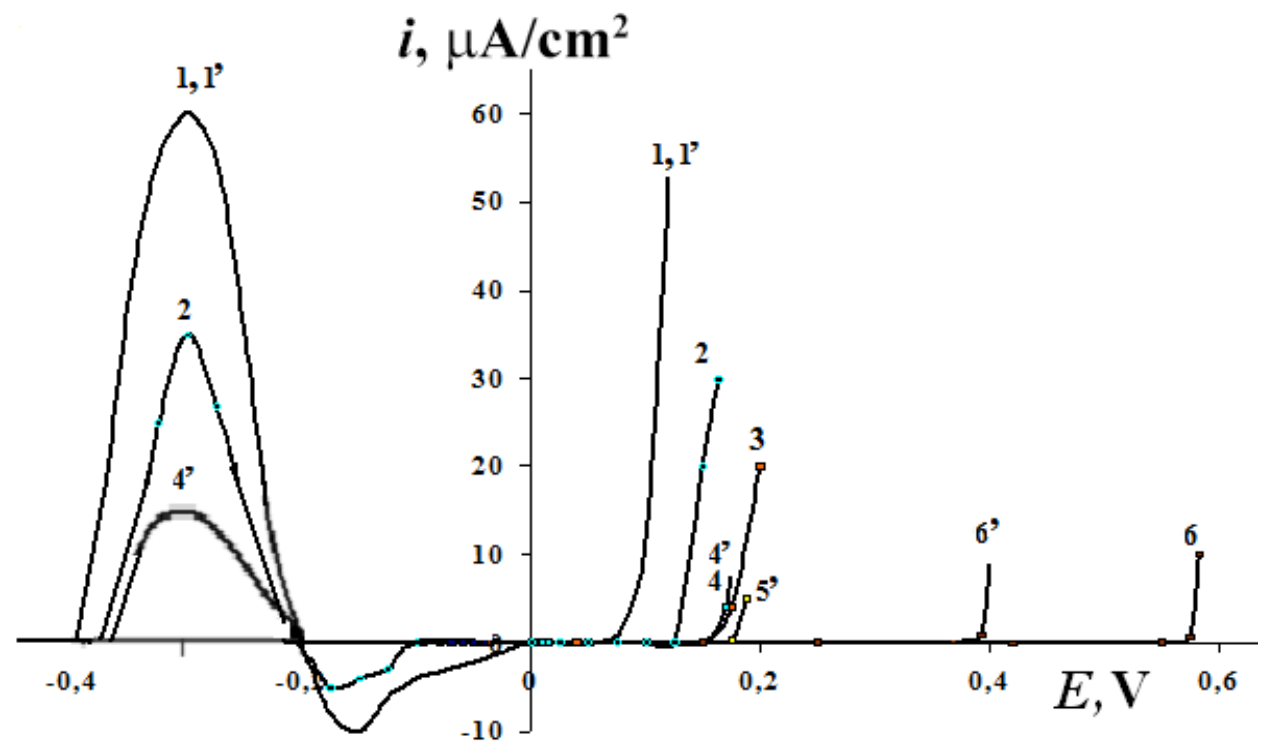

Figure 2. Anodic polarization curves of mild steel St 3 in borate buffer with $\mathrm{pH} 7.4$ containing $0.01 \mathrm{M} \mathrm{NaCl}$, without $\left(1,1^{\prime}\right)$ and with addition of SDOP, mmol/1: $2-0.025 ; 3-0.05 ; 4,4{ }^{\prime}-$ $0.10 ; 5^{\prime}-0.50 ; 6.6^{\prime}-1.00$. Exposure of the electrode in the solution prior to anodic polarization: $90 \mathrm{~min}-1-4,6$; $15 \mathrm{~min}-1$ ', 4' -6 '. 
In fact, upon increase in exposure time from 15 to $90 \mathrm{~min}$, complete passivation is observed already at $C_{\mathrm{in}}=0.05 \mathrm{mmol} / \mathrm{L}$ and, at $C_{\mathrm{in}}=1 \mathrm{mmol} / \mathrm{L}$, the $E_{\mathrm{pit}}$ value increases by $0.5 \mathrm{~V}$.

The temperature $t$ is yet another factor that can substantially affect the passivation of steel in SDOP solutions. With an increase in $t$ to $60^{\circ} \mathrm{C}$, steel becomes passive at $C_{\text {in }}=$ $0.1 \mathrm{mmol} / \mathrm{L}$. However, in this case $E_{\text {pit }}$ can shift in the negative direction. This was explained as follows. Being adsorbed on active sites, SDOP hampers oxide film growth, but its concentration is insufficient for protecting the passive state from chloride ions under high temperature conditions, as a result of which local depassivation takes place at a more negative potential.

An increase in the exposure of the electrode to the solution at elevated $t$ can also play a substantial role [10]. In contrast to room temperature, where mild steel is spontaneously passivated at $C_{\mathrm{SDOP}}=0.10 \mathrm{mmol} / \mathrm{l}$, though its depassivation by chlorides is facilitated, at the same $C_{\mathrm{SDOP}}$ and an exposure time of $90 \mathrm{~min} E_{\mathrm{pit}}$ is shifted in the positive direction from the reference value in the blank solution. This indicates that a protective layer is formed that is more resistant to chlorides.

It is worth recalling that A.N. Frumkin et al. [25] noted that the passivation of metals is explained not so much by changes in the structure of the double layer but rather by changes in the chemical nature of the surface. The latter is often achieved upon adsorption of anions, with their bonding to the surface strengthened as the potential is shifted to more positive values. Consequently, anion-active inhibitors with a tendency to chemisorption should promote adsorptive passivation of iron in neutral media. According to [26], these anions hydrophobize the surface, have an action that can also impede the growth of the oxide film. In this respect, a significant effect should be expected from anions containing a substantial number of hydrocarbon radicals.

SDOP can hamper the growth of an oxide film on steel to such an extent that a nonoxide passivation mechanism can take place. This has been proved in [10] by an in situ method (galvanostatic coulometry). When this method was used in the reduction of the passive film on steel, no potential delays corresponding to the reduction of iron oxides were detected on the $E$-time curves. It is assumed that the determining role in the passivation of steel in the presence of SDOP in aqueous solution belongs to its chemisorption that suppresses the dissolution of steel over a wide range of potentials.

It is not surprising that the hydrophobicity of organic anions present in a solution, which was characterized by $\log D$ and calculated from $\log P^{1}$ taking into account the $\mathrm{pH}$ and $\mathrm{p} K_{\mathrm{a}}$ of the corresponding acid [28], often largely determines the efficiency of their passivating action. This was already discussed in the first and second parts of the review $[29,30]$ with regard to passivating carboxylate anions.

\footnotetext{
${ }^{1} P$ is the partition coefficient of a chemical compound in the system of two immiscible liquids, octanolwater [27].
} 
Judging by the value of $\log D=2.95$ at $\mathrm{pH} 7.0$ [29], the SDOP anion should have high hydrophobicity and hence surface activity. The presence of a phosphate group in the SDOP molecule should also facilitate strong adsorption of its anion on mild steel, both preoxidized and free of surface oxide. In fact, ellipsometric measurements on mild steel in borate buffer with $\mathrm{pH} 7.4$ confirmed that SDOP has high adsorption capability of SDOP (Figure 3).

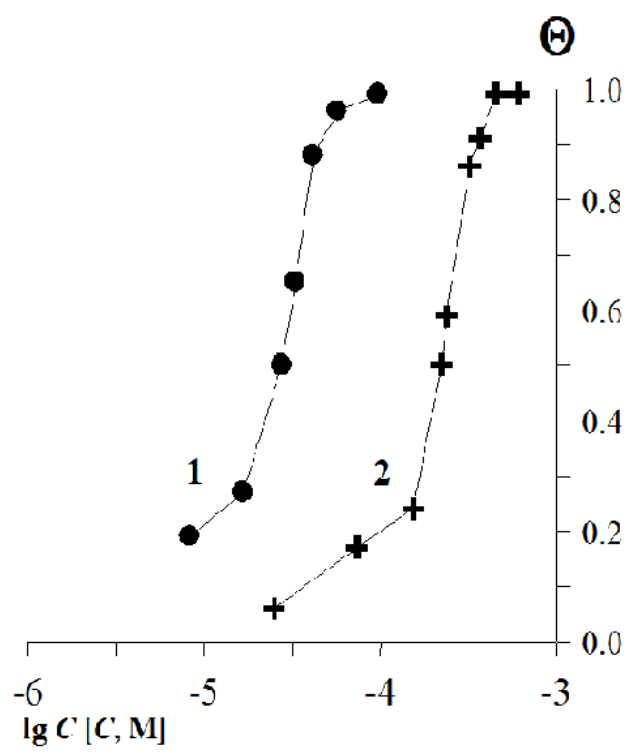

Figure 3. Adsorption isotherms of SDOP obtained on mild steel in borate buffer, $\mathrm{pH} 7.36$, at $E=-0.65 \mathrm{~V}(1)$ and $E=0.2 \mathrm{~V}(2)$.

In these measurements, which were previously described in more detail $[3,5,10,29-$ 31 ], the change in the ellipsometric angle $\left(\delta \Delta=\Delta-\Delta_{0}\right.$, where $\Delta$ is the measured angle established after the addition of the adsorbate to the solution, and $\Delta_{0}$ corresponds to the surface before the addition of the adsorbate being studied) as a function of the adsorbate concentration $\left(C_{\mathrm{in}}\right)$, can be used to determine the type of the adsorption isotherm. The adsorption isotherms are built using the plot of $(-\delta \Delta) v s . C_{\text {in }}$, assuming that the plateau of this value corresponds to a coverage degree of the surface by the adsorbate $\Theta \rightarrow 1.0$.

The resulting isotherms can satisfactorily be approximated by Frumkin's equation:

$$
B C=[\Theta /(1-\Theta)] \exp (-2 a \Theta),
$$

where $a$ is the attraction factor that characterizes the interaction between the adsorbate particles and $B$ is the adsorption equilibrium constant related to the free adsorption energy $\left(-\Delta G_{\mathrm{A}}^{0}\right)$ as follows: $B=(1 / 55.5) \exp \left(-\Delta G_{\mathrm{A}}^{0}\right) / R T$. When the Frumkin isotherm is built in the coordinates: $X=\Theta ; Y=\ln \{\Theta /[(1-\Theta) C]\}$, the Y-intercept provides the $\ln B$ value. The adsorption energy of SDOP on the steel at $E=-0.65 \mathrm{~V}$ was found from the estimated $B$ constant (L/mol): $\left(-\Delta G_{\mathrm{a}}^{0}\right)=32.06 \pm 1.6 \mathrm{~kJ} / \mathrm{mol}, a=1.7 \pm 0.1$. The adsorption energy of 
SDOP on the steel at $E=0.2 \mathrm{~V}$ is substantially lower: $\left(-\Delta G_{\mathrm{a}}^{0}\right)=26.4 \pm 1.3 \mathrm{~kJ} / \mathrm{mol}, a=$ $1.65 \pm 0.1$.

When comparing $\left(-\Delta G_{\mathrm{a}}^{0}\right)$ values on an oxidized electrode at $E=0.2 \mathrm{~V}$ on low-carbon steel with $\left(-\Delta G_{\mathrm{a}}^{0}\right)=28 \pm 1.4 \mathrm{~kJ} / \mathrm{mol}$ measured on pure iron [5], it can be noted that the adsorption isotherms of SDOP nearly coincide within the accuracy of the experiment. Adsorption of SDOP on oxidized iron and steel surfaces takes place in the same concentration range. This allows us to assume that SDOP is less sensitive to the presence of various inclusions in steels than many salts of carboxylic acids, e.g., phenylanthranilic acid and its derivatives [31].

The flow velocity of the environment is yet another factor that beneficially affects the passivating ability of SDOP. Polarization anodic curves obtained on a rotating disk electrode $(v=0.8 \mathrm{~m} / \mathrm{s})$ made of mild steel at $t=60^{\circ} \mathrm{C}$ with electrode exposure for $15 \mathrm{~min}$ showed that, even at $C_{\mathrm{SDOP}}=0.2 \mathrm{mmol} / 1, E_{\mathrm{pit}}$ increases by $0.30 \mathrm{~V}$, while at $C_{\text {in }}=1 \mathrm{mmol} / \mathrm{l}$, $E_{\text {pit }}$ increases to $0.77 \mathrm{~V}$. Thus, agitation of the solution promotes better protection of mild steel with SDOP against local depassivation by chlorides.

SDOP manifests passivating properties not only toward Fe and steels but also toward other metals and alloys. Thus, as early as in [5], SDOP was found to facilitate the passivation of zinc and aluminum alloy D16 passivation in an aqueous chloride solution. Since alloys of the $\mathrm{Al}-\mathrm{Mg}-\mathrm{Cu}$ system have poor corrosion resistance in aqueous environments and in humid atmospheres [32], coatings containing anticorrosive pigments are often used to protect items made of these alloys. Organic passivators, including SDOP, attracted the attention of researchers in view of the replacement of environmentally hazardous chromate pigments need replacement.

S.V. Oleinik et al. [7] studied the adsorption of SDOP anions on the surface of D16 alloy from a borate buffer solution ( $\mathrm{pH}$ 7.4) by ellipsometry. In these studies of this kind, it is necessary to have an initial electrode surface with ellipsometric parameters - the angles $\Delta$ and $\psi$ angles - stable over time, because it is only in this case that the change in $\Delta$ of the electrode upon addition of the inhibitor addition to the solution can be attributed to its adsorption. However, ellipsometric studies of a D16 alloy electrode in borate buffer at $E=$ $-0.3 \mathrm{~V}$ showed that the $\Delta$ value was changing for a long time. It did not reach a steadystate value, probably due to the formation of a hydrated oxide with variable composition on the alloy surface.

To avoid ambiguity in the interpretation of ellipsometric angles for electrodes with a thick oxide layer, the authors used the method where thin passivating layers were preformed on the alloy. Such a film was formed on D16 alloy by treatment of the electrode in $50 \% \mathrm{HNO}_{3}$ for $3 \mathrm{~min}$, which ensured the stability of the electrode ellipsometric parameters in borate buffer at $E=-0.3 \mathrm{~V}$ for $120 \mathrm{~min}$. After this preliminary passivation of the alloy, we observed a slight increase (by about $0.10 \mathrm{~V}$ ) on the anodic polarization curve obtained in the background solution. This indicates that the oxide film on the electrode is less defective. 
Measurements of adsorption on this electrode at $E=-0.30 \mathrm{~V}$ showed that it was adequately described by Eq. (1) with $\left(-\Delta G_{\mathrm{a}}^{0}\right)=33.8 \pm 0.2 \mathrm{~kJ} / \mathrm{mol}$ and $a=1.4 \pm 0.3$. It can be seen that the adsorption energy of SDOP on D16 alloy is even slightly higher than in the case of oxidized low-carbon steel. Apparently, the adsorption of anions has a chemisorption character, although formally it is described by the Frumkin isotherm. Therefore it is not surprising that the aqueous extract of the calcium salt of the acid is at least not inferior to a similar extract of zinc chromate in the protection efficiency of alloy D16 against pitting [7].

Other acidic organic phosphoric acid esters also possess adsorption activity on aluminum and its alloys. In this respect, it is interesting to compare two surfactants, sodium dodecyl sulfate (SDS) and sodium dodecyl phosphate (DDP). These studies performed by P. Carlson et al. [8, 9, 33-35] were initiated by the need to prevent corrosion of aluminum microparticles that may be used as pigments in waterborne printing "silver" inks or in protective primers.

The surface of an aluminum pigment is always covered with a thin oxide layer, hence the interaction of a surfactant with alumina in an aqueous solution is actually considered. Analysis of the results of a study on surface modification by various surfactants for corrosion inhibition of aluminum pigments in water [33] led to the assumption that the electrostatic interaction of surfactants with the Al surface alone is insufficient for good protection. It was concluded that effective corrosion inhibition provided by organophosphate anions may be due to chemisorption, possibly involving a bridging bidentate complex, as well as the ability to form stable complexes with Al(III).

In fact, it was shown [34] that DDP provided very effective protection of pigments. Like the other phosphates studied (Alk $=\mathrm{C}_{14} \mathrm{H}_{29}, \mathrm{C}_{16} \mathrm{H}_{31}$ and $\mathrm{C}_{18} \mathrm{H}_{35}$ ), the minimum concentration where DDP starts to be effective as a corrosion inhibitor is around or below the critical micelle concentration (CMC). On the other hand, SDS is completely ineffective as an inhibitor, even though its adsorption isotherm is about the same as that of DDP. This difference was explained by the formation of various types of complexes with the alumina surface. Outer-sphere complexes are assumed for SDS, whilst DDP can form more stable inner-sphere complexes. Since methyl phosphate, which is not a surfactant, does not provide sufficient anticorrosion protection, it was concluded that surface activity is crucial for inhibition, and the use of phosphates as inhibitors insufficient for adequate protection. Thus, an effective inhibiting anion should have a phosphate anchor group and a long enough alkyl to provide a high surface activity in aqueous solution.

Further studies of SDS and DDP adsorption on Al and its oxide using quartz crystal microbalance techniques with dissipation monitoring (QCM-D), XPS and atomic adsorption spectrometry (AAS) confirmed advantage of an organophosphate corrosion inhibitor [8]. The stronger hindrance of aluminum dissolution by DDP compared to SDS was explained by the assumption that DDP forms a more compact protective layer with lower permeability on the aluminum surface than SDS. 
The adsorption of these surfactants was also studied by atomic force microscopy (AFM) on an Al oxide deposited on a silicon wafer by thermal evaporation in vacuum. The thickness of the $\mathrm{Al}$ oxide layer was about $120 \mathrm{~nm}$. In order to identify the differences in the adsorption of the surfactants, its structure and dynamics, images obtained by AFM on a pure alumina-coated silicon wafer and a wafer after exposure to SDS and DDP solutions were compared.

In the case of a sample exposed to an SDS solution, the changes in the AFM image were negligible, which was attributed to a very weak adsorption and a weak bond of the surfactants with the alumina surface. After exposing the sample in a DDP solution, large patches were seen on the alumina layer, and a cross section of the images shows that the patch thickness was about 3-4 nm. AFM studies showed strong adsorption of DDP with formation of a bilayer spotted film, whereas DDS adsorption from aqueous solutions is so weak that it is not found on AFM images. The surface associates of DDP do not change for a long time, i.e., their desorption from the alumina surface and rearrangement are slow.

AFM study revealed another interesting feature of DDP adsorption. It was shown that only $63 \%$ of Al oxide surface was covered with patches of DDP bilayers. This clearly demonstrates that a full coverage of a surfactant bilayer is not needed to obtain satisfactory inhibition of Al pigment powder in aqueous solution. The set of results obtained by this method can be a serious argument in favor of the assumption of DDP chemisorption.

This hypothesis well agrees with the high protective capability of DDP with respect to Al oxide even in more corrosive solutions, for example, those containing ethanolamines that are used since they evaporate from the drying ink matrix, thus minimising problems with precipitation of the polymeric binder as a salt [35]. However, ethanolamines may form water soluble complexes with $\mathrm{Al}(\mathrm{III})$ and increase the dissolution rate of $\mathrm{Al}$ oxide. It is important that DDS only inhibits this dissolution, whereas DDP stops it.

Organophosphates, such as dialkyl or diphenyl phosphate, etc. can be not only effective corrosion inhibitors of $\mathrm{Al}$ alloys by themselves but can also increase the protective effects of other inhibitors. For example, M. Forsyth et al. [36] noticed that diphenyl phosphates (DPP) of rare earth metals (REM) provide the best protection against corrosion of these alloys than many similar salts of carboxylic acids. They believe that the synergism of protection by such salts is associated with the difference in the mechanism of their action. REM cations, primarily $\mathrm{Ce}^{3+}$, predominantly inhibit the cathodic reaction, whereas organic anions inhibit the anodic reaction. Previously, it was observed [37-39] that $\mathrm{REM}(\mathrm{DPP})_{3}$ or REM dibutyl phosphates (DBP) were able to suppress filiform corrosion in the case of a defective epoxy coating on aluminium alloy AA 2024. It was found that $\mathrm{Ce}(\mathrm{DBP})_{3}$ provided better protection than $\mathrm{CeCl}_{3}$, without formation of significant corrosion products, substantial pitting or reprecipitation of copper on the surface alloy. Corrosion protection seems to be enhanced at higher concentrations of $\mathrm{NaCl}$, suggesting that the inhibiting film is more readily deposited when some corrosion occurs. Electrochemical studies have confirmed that the REM salts of these organophosphates retard both electrode reactions, i.e., they are corrosion inhibitors of mixed type. 
XPS analysis of the surface confirmed the presence of both $\mathrm{Ce}^{3+}$ and $\mathrm{Ce}^{4+}$. Its analysis by secondary ion mass spectroscopy (SIMS) clearly indicated the presence of a $500 \mathrm{~nm}$ layer containing cerium after 10 days of immersion of the alloy in a $\mathrm{Ce}(\mathrm{DBP})_{3}$ solution. The SIMS experiment also detected a strong phosphorus signal.

Based on these studies, it was concluded that inhibitors bind to an aluminum alloy through a phosphate group, forming a bimetallic complex with $\mathrm{Al}$ and REM. The nature of the species in the solution adjacent to the surface plays a major role in the efficiency of the inhibiting film. For example, it has shown that $\mathrm{Ce}(\mathrm{DPP})_{3}$ remained in solution as a complex in the $\mathrm{pH}$ range 5.5-7.0 rather than separated into individual $\mathrm{Ce}^{3+}$ and $\mathrm{dpp}^{-}$. The bimetallic complex may not only be part of the protective film but also undergo hydrolysis due to local alkalizing of the solution layer close to the surface caused by the cathodic reaction of oxygen reduction. The local $\mathrm{pH}$ changes can also lead to the formation of a $\mathrm{CeO}(\mathrm{OH}) / \mathrm{Ce}(\mathrm{OH})_{3}$ deposit.

The relatively low solubility of $\mathrm{Ce}(\mathrm{DPP})_{3}$ in water may allow it to be an effective corrosion inhibitor for polymeric coatings, and its release from the coating will control protection of the aluminum alloy from corrosion. In particular, a salt of mischmetal (a REM mixture containing $\geq 50 \%$ cerium) with DPP is capable of providing corrosion inhibition not worse than chromates at a lower inhibitor concentration.

Later [40], studies on the corrosion protection of aluminum alloy AA2024-T3 by $\mathrm{Ce}(\mathrm{DBP})_{3}$ as an inhibitor were continued using SEI and scanning electron microscope (SEM) analysis in combination with X-ray dispersive spectroscopy (RDS). The combination of these techniques provides information on the mechanism of electrochemical reactions and their deposition products, together with characterization of the alloy surface, allowing to distinguish the effect of inhibitors on different parts of its heterogeneity. A detailed SEM-RDS study identified different features associated with corrosion attack on the matrix, around intermetallic compounds and stable pitting sites. The EIS study highlighted that the use of different inhibitors directly affects the selection of "the most probable equivalent circuits (MPEC)" and that, as a consequence, MPECs existing in literature are not necessarily applicable to each system studied. It was shown that cathodic protection with $\mathrm{CeCl}_{3}$ is based on the prevention of localized attack at intermetallides, but the processes occurring below the surface cannot be stopped by $\mathrm{Ce}^{3+}$ cations. On the contrary, $\mathrm{Ce}(\mathrm{DBP})_{3}$ offers a combined effect due to cerium oxide formation on $\mathrm{Cu}$-rich areas while $\mathrm{dbp}^{-}$is adsorbed on the entire surface. The adsorbed layer of $\mathrm{DBP}^{-}$ on the alloy surface is a stable barrier for $\mathrm{Cl}^{-}$and increases the deposition of $\mathrm{Ce}$ to $\mathrm{Cu}$-rich sites. Such a bi-functional inhibitor limits the formation of corrosion plumes and rings, the presence of which is a clear indication of the subsurface localized attack.

Probably, the adsorption of mono- and dialkyl phosphates from aqueous solutions on $\mathrm{Mg}$ or its alloys and their protective properties with respect to this metal have been studied least thoroughly. $\mathrm{Mg}$ alloys have many technological advantages over other alloys, but they are markedly inferior to aluminum alloys in corrosion resistance. However the interest in $\mathrm{Mg}$ alloys has been increasing in many industries in the past decades, therefore the 
protection of these alloys from corrosion deserves special attention. The traditional corrosion protection methods for $\mathrm{Mg}$ alloys (chromate treatment and paint coatings containing chromate pigments or inhibitors) have been facing serious environmental objections in recent years. Although chromate is the best-studied and very efficient corrosion inhibitor of $\mathrm{Mg}$ and its alloys, its toxicity and hazard to the environment makes it necessary to replace chromate in various technologies.

In view of this, it is interesting to compare the protective effect of potassium dichromate, SDOP, and the known corrosion inhibitor 5-chloro-1,2,3-benzotriazole (ClBTA) in relation to industrial magnesium Mg-90 (mass\%: $\mathrm{Mg} 99.9, \mathrm{Fe} \leq 0.04, \mathrm{Mn} \leq 0.03$, $\mathrm{Al} \leq 0.02, \mathrm{Ni} \leq 0.001, \mathrm{Cu} \leq 0.004, \mathrm{Si} \leq 0.009, \mathrm{Cl} \leq 0.005)$ in aqueous solutions with $\mathrm{pH} 7.4$ and 9.2 [41]. In borate buffer $\mathrm{pH} 7.4$, even in the absence of chlorides, Cl-BTA is a weak corrosion inhibitor $(Z=36.6 \%)^{2}$ that is inferior in efficiency not only to dichromate but also to SDOP that slows down both the anodic and cathodic reactions on Mg-90 [12]. Therefore, it is not surprising that SDOP exhibits good protective properties at $C_{\text {in }}=1.0$ $\mathrm{g} / \mathrm{l}$, both by itself and in combinations with other corrosion inhibitors.

Increasing the $\mathrm{pH}$ to 9.2 confirms the protective properties of SDOP, Cl-BTA and chromate (Figure 4). The organic inhibitors become more effective in slightly alkaline solutions, which is partly due to a decrease in the corrosiveness of the background solution [40]. To increase the corrosiveness of a weakly alkaline solution, sodium chloride was added and further studies were carried out in a borate solution containing $10 \mathrm{mM} \mathrm{NaCl}$. The corrosion rate of Mg-90 in this solution is $3.23 \mathrm{~g} / \mathrm{m}^{2} \cdot \mathrm{h}$ at $1 \mathrm{~h}$ exposure but decreases with time $(12 \mathrm{~h})$ to $K=2.06 \mathrm{~g} / \mathrm{m}^{2} \cdot \mathrm{h}$ due to protective properties of the hydroxide film. A small addition of SDOP $(1.0 \mathrm{mM})$ can provide $Z=90.1 \%$. With an increase in $C_{\text {SDOP }}, Z$ decreases, but a combination of SDOP with Cl-BTA increases the protection of $\mathrm{Mg}$. In fact, the $5.0 \mathrm{mM} \mathrm{Cl-BTA}+5.0 \mathrm{mM}$ SDOP combination provides $\mathrm{Z}=94.1 \%$, i.e., it is higher than that achieved by SDOP and especially by Cl-BTA even at much higher $C_{\mathrm{in}}$.

An important feature of the effect of the corrosion inhibitors studied on $\mathrm{Mg}$ corrosion is that $Z$ changes with time. It is essential that the decrease in the protective effect of SDOP cannot be explained by the fact that $C_{\mathrm{SDOP}}$ is small and insufficient to block the metal surface. This is indicated by the fact that a growth in $C_{\mathrm{SDOP}}$ above $5.0 \mathrm{mM}$ (at the same test duration) decreases the $Z$ of SDOP rather than increases it. It can be assumed that SDOP, like organic complexing agents [3], can form water-soluble compounds with the cations of the metal being protected. This can have a negative effect on the formation of a protective oxide-hydroxide film on $\mathrm{Mg}$ surface, that is why small SDOP concentrations are promising for improving the protective action of Cl-BTA on $\mathrm{Mg}$.

\footnotetext{
${ }^{2} \mathrm{Z}(\%)=\left[\left(\mathrm{K}_{\mathrm{b}}-\mathrm{K}_{\mathrm{in}}\right) / \mathrm{K}_{\mathrm{b}}\right] \cdot 100$, where $\mathrm{K}_{\mathrm{b}}$ and $\mathrm{K}_{\mathrm{in}}$ are the corrosion rates of the metal in the background solution without and with addition of the corrosion inhibitor, respectively.
} 


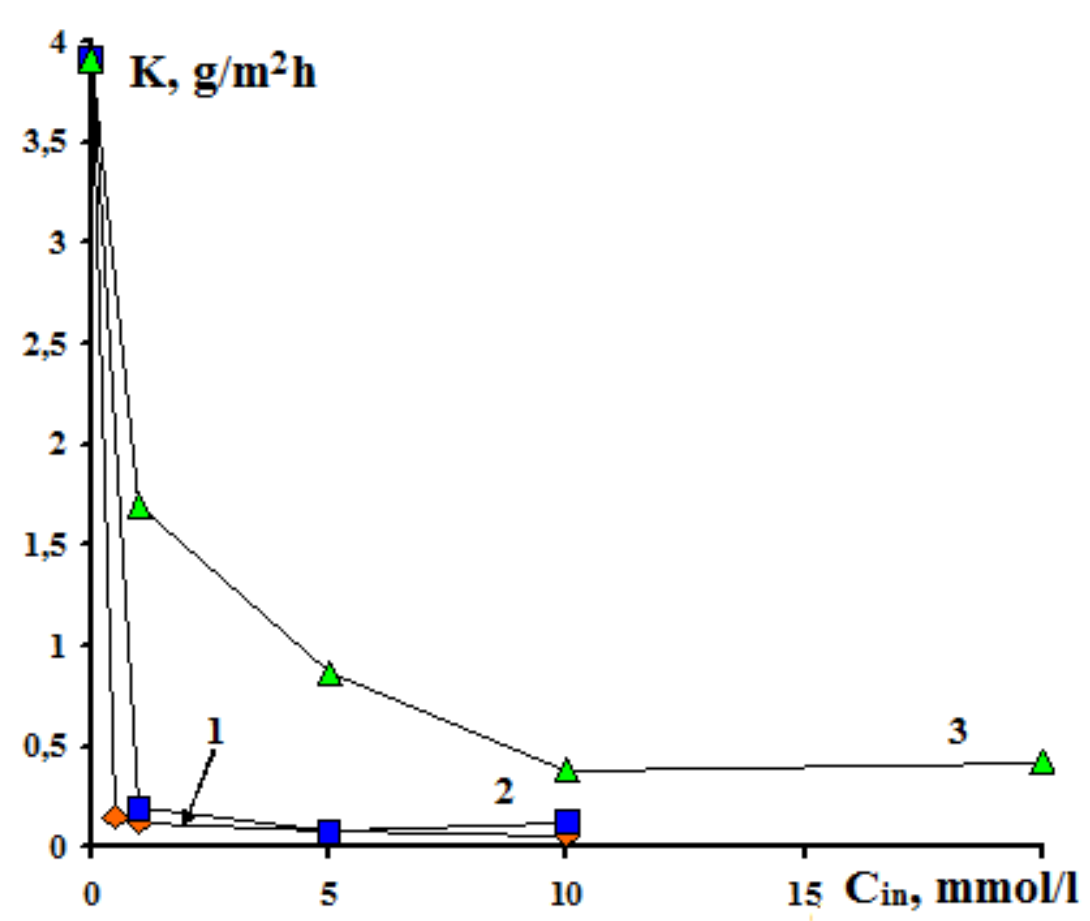

Figure 4. The dependence of corrosion rates of $\mathrm{Mg}-90$ in borate solution with $\mathrm{pH} 9.2$ on the concentrations of potassium dichromate (1), SDOP (2) and Cl-BTA (3).

The protection of $\mathrm{Mg}$ by a mixture of triazole with SDOP can be improved by adding a small amount of silane, e.g., vinyltrimethoxysilane (VS), though it poorly inhibits the corrosion of $\mathrm{Mg}$. Indeed, addition of as little as $1.0 \mathrm{mM}$ of VS to the mixed inhibitor (4.0 mM Cl-BTA + $1.0 \mathrm{mM}$ SDOP) increases $Z$ from 87.9 to $90.7 \%$ in a shorter test $(1 \mathrm{~h})$, and from $75.7 \%$ to $83.5 \%$ in a longer test $(12 \mathrm{~h})$. A fivefold increase in $C_{\mathrm{VS}}$ slightly increases $Z$, to 91.0 and $84.5 \%$ respectively, but it is more effective to increase the content of the mixed inhibitor itself in the solution to achieve $Z=95.7$ and $89.3 \%$, respectively. In those solutions without VS it is $8.0-12.6 \%$. It was assumed that VS is included in the protective adsorption layers formed by corrosion inhibitors on $\mathrm{Mg}$, and its ability to first hydrolyze to silanol and then to form a siloxane structure provides an additional protective effect. Although the ternary blend protects $\mathrm{Mg}$ better than the binary one, it is still inferior to dichromate in corrosion inhibition in aqueous chloride solutions. However, chromate passivation of magnesium is not as effective in the protection against atmospheric corrosion, and treatment of $\mathrm{Mg}$ in an aqueous solution of the ternary composition can create a passivation film that is not inferior to chromate but even exceeds its protective effect in a heat-and-moisture chamber (Figure 5).

In the absence of a passivating treatment, the first corrosion damage that rapidly increases with time can be seen in $30 \mathrm{~min}$ on $\mathrm{Mg}$ samples placed in a $100 \%$ relative humidity chamber. Preliminary processing of the samples in a slightly alkaline $5.0 \mathrm{mM}$ SDOP solution at $t=20^{\circ} \mathrm{C}$ protected them from corrosion for $\tau=2.0 \mathrm{~h}$, whereas rising the temperature weakened the protection of $\mathrm{Mg}$. Chromate treatment provided $\mathrm{Mg}$ protection for 3.0 hours, regardless of $t$. The passivation of $\mathrm{Mg}$ samples in a slightly alkaline solution 
of an inhibitor blend (4.0 mM Cl-BTA + 1.0 mM DOP) provides the best protection at $t=$ $20^{\circ} \mathrm{C}(\tau=2.5 \mathrm{~h})$. However, to achieve the effect of chromate treatment, its $C_{\text {in }}$ has to be increased 4-fold. Use of the ternary mixture $(1.0 \mathrm{mM}$ SDOP $+4.0 \mathrm{mM} \mathrm{Cl-BTA}+5.0 \mathrm{mM}$ VS) at $\mathrm{t}=20^{\circ} \mathrm{C}$ increases $\tau$ to $5.0 \mathrm{~h}$, while increasing the $C_{\mathrm{VS}}$ in the mixture to $10.0 \mathrm{mM}$ gives $\tau=5.5 \mathrm{~h}$. Such passivation increases the time until the first corrosion damage on $\mathrm{Mg}$ 10 -fold, and its efficiency is $1.5-2$ times higher than that of chromate treatment.

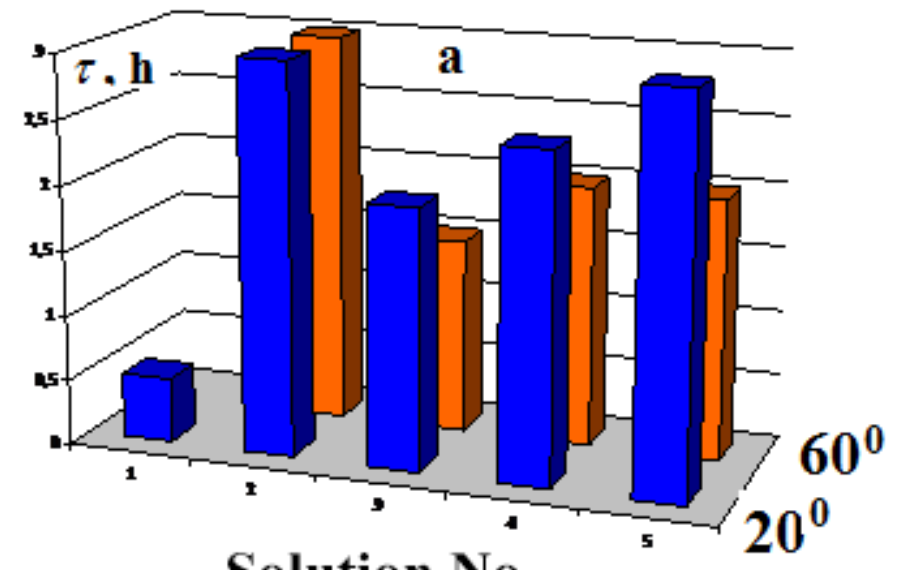

Solution No.

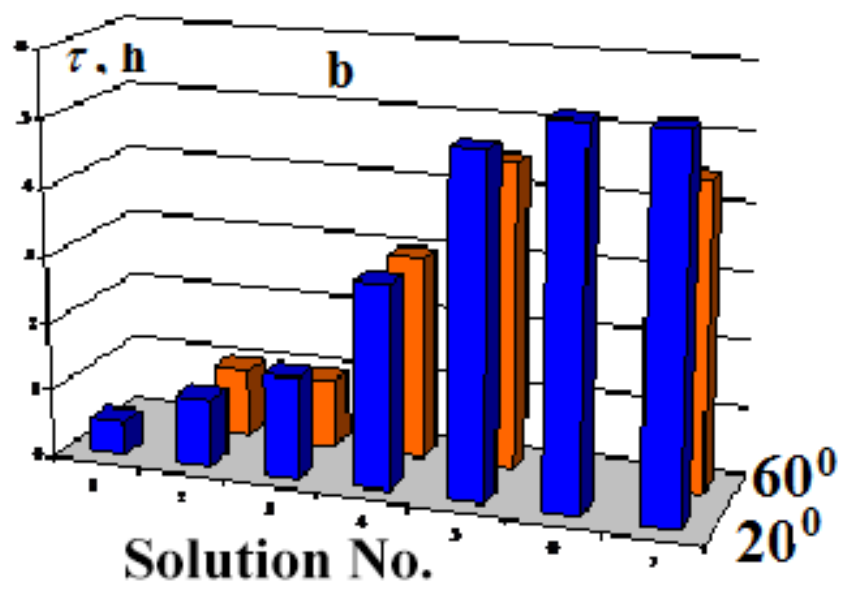

Solution No.

Figure 5. The dependence of the time until the first corrosion damage on $\mathrm{Mg}$ plates placed in a heat-and-moisture chamber without (1) and with preliminary treatment (2-9) in a stirred ( $V=0.3 \mathrm{~m} / \mathrm{s}$ ) solution, $\mathrm{pH} 9.2, t=20$ or $60^{\circ} \mathrm{C}$, containing (in mmol/l): a) $2-5.0 \mathrm{~K}_{2} \mathrm{Cr}_{2} \mathrm{O}_{7}$; 3 - 5.0 SDOP; 4 - 4.0 Cl-BTA+1.0 SDOP; 5 - 16 Cl-BTA+4 SODP (4:1); b) 2 - 5 VS; 3 $10 \mathrm{VS} ; 4-1.0 \mathrm{SDOP}+5.0 \mathrm{VS} ; 5-4.0 \mathrm{Cl}-\mathrm{BTA}+1.0 \mathrm{SDOP}+5.0 \mathrm{VS} ; 6-12.0 \mathrm{Cl}-\mathrm{BTA}+$ $3.0 \mathrm{SDOP}+5.0 \mathrm{VS} ; 7-4.0 \mathrm{Cl}-\mathrm{BTA}+1.0 \mathrm{SDOP}+10.0 \mathrm{VS}$.

The important role of SDOP in the protective effect of the mixed inhibitors is also supported by the XPS results obtained after exposure of Mg samples in water containing SDOP [41]. In all cases, they confirmed the presence of SDOP in the surface layers, as the peak of $\mathrm{P} 2 p$ electrons appears in the spectrum. Although ultrasonic cleaning of the sample in isopropanol decreases the intensity of this peak, the remaining particles of the organic inhibitor form a chemisorbed layer on the surface due to replacement of the oxygen atom linked to the magnesium cation by oxygen atoms of the phosphate group. The thickness of the SDOP layer after ultrasonic washing is not more than $0.8 \mathrm{~nm}$, which may correspond to dense packing of its particles on the surface. From these studies, it was concluded that the protection of $\mathrm{Mg}$ by mixed inhibitors is associated with the formation on its surface of a protective film consisting of an $\mathrm{Mg}$ hydroxo-oxide that is covered by at least one monolayer of organic molecules.

In view of the assumption about SDOP chemisorption on oxidized $\mathrm{Mg}$ surface, it was of interest to evaluate the $\left(-\Delta G_{\mathrm{A}}^{0}\right)$ value of the corrosion inhibitor on it by measuring the isotherm of SDOP adsorption using an in situ method. Recently, a procedure using the 
ellipsometric method was developed in our laboratory to obtain the adsorption isotherms of corrosion inhibitors in a borate solution with $\mathrm{pH} 11.2$ [13]. To do this, it was necessary to obtain a stable oxidized $\mathrm{Mg}$ surface on which the ellipsometric angles $\Delta$ and $\Psi$ stop changing with time.

The electrode was polished with emery paper and with diamond paste, degreased with acetone, and then placed in a $5 \mathrm{M} \mathrm{NaOH}$ solution. After $1.5 \mathrm{~h}$, the oxide thickness reached $60-70 \mathrm{~nm}$ and the electrode was transferred to a borate solution with $\mathrm{pH} 11.2$. In $24 \mathrm{~h}$, the electrode potential stabilized at $E_{\text {cor }}=-0.2 \mathrm{~V}$ and, though the oxide film thickness increased by $20 \mathrm{~nm}$, the surface remained mirror-like. The electrode was maintained for $1.5 \mathrm{~h}$ at a potential $20 \mathrm{mV}$ more negative than $E_{\text {cor }}$ using a potentiostat. After that time, the ellipsometric angles stopped changing. The surface remained "stable", i.e., the ellipsometric angles remained unchanged for $6-7 \mathrm{~h}$. This allowed us to add an inhibitor concentrate to the solution and to conduct ellipsometric measurements in which the angle changes $(-\delta \Delta)$ can be attributed to adsorption of the inhibitor (Figure 6).

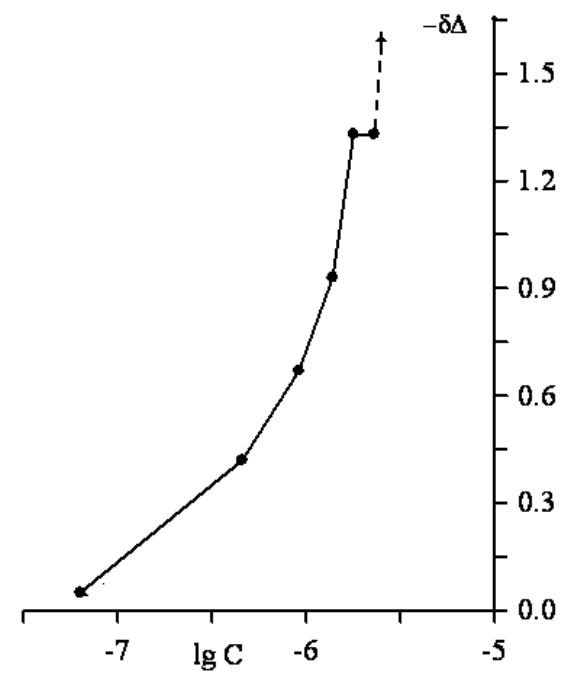

Figure 6. Changes in the $\Delta$ angle upon adsorption of SDOP on oxidized magnesium from a borate solution with $\mathrm{pH}$ 11.2. The last point was obtained without reaching a steady $\Delta$ value.

As follows from analysis of the $(-\delta \Delta) v s . \lg C$ plot presented in Figure 6, upon adsorption of the SDOP, the plateau on it corresponding to a conditional monolayer filling of the surface is found at $\sim 1.3^{\circ}$. All points, including the plateau, were recorded after the readings became stable in time. However, after the formation of a "conditional" monolayer with an increase in $C_{\mathrm{in}}$, the $\Delta$ angle varies over time, which indicates further adsorption of the inhibitor. This part of the curve in Figure 6 is marked with a dashed line, and the point that is shown is not an equilibrium value.

Since the changes in $(-\delta \Delta)$ are proportional to the thickness of the adsorbed layer and in general case are related to the molecule length, it can be assumed that the SDOP anions are adsorbed vertically to the surface, like on iron, St3 steel $[5,10]$, or D-16 alloy [7]. Calculation using the Temkin equation 


$$
\Theta=1 / f \ln [B C]
$$

gives $\left(-\Delta G_{\mathrm{a}}^{0}\right)=50.2 \pm 2.5 \mathrm{~kJ} / \mathrm{mol}$, which is significantly higher than in the case of the other metals that we studied. This value allows us to assume that chemisorption of SDOP on magnesium occurs, and the value $f=5.5 \pm 0.5$ indicates a significant energy inhomogeneity of the oxidized surface of $\mathrm{Mg}$. Since the plateau on the isotherm is very "narrow", it can be assumed that the SDOP adsorption does not involve all active centers on the surface of the electrode and $\mathrm{Mg}$ is again oxidized on them or the metal cations that pass into the solution form compounds with the inhibitor and begin to adsorb to form more layers.

The high adsorption capacity of SDOP allows it to be a corrosion inhibitor toward not only technically pure $\mathrm{Mg}$ but also its alloys. This has recently been demonstrated by studying the anodic dissolution of the WE43 alloy (mass\%: $91.35 \mathrm{Mg}, 4.16 \mathrm{Y}, 3.80$ rare earth elements, $0.36 \mathrm{Zr}, 0.20 \mathrm{Zn}, 0.13 \mathrm{Mn}$ ) in neutral chloride solutions [42, 43]. As can be seen in Figure 7, SDOP can slow down significantly the dissolution of the alloy even at a concentration 5 times lower than $C_{\mathrm{NaCl}}$, so it is almost not inferior in this respect to sodium oleate, one of the most effective corrosion inhibitor of carboxylate type for $\mathrm{Mg}$.

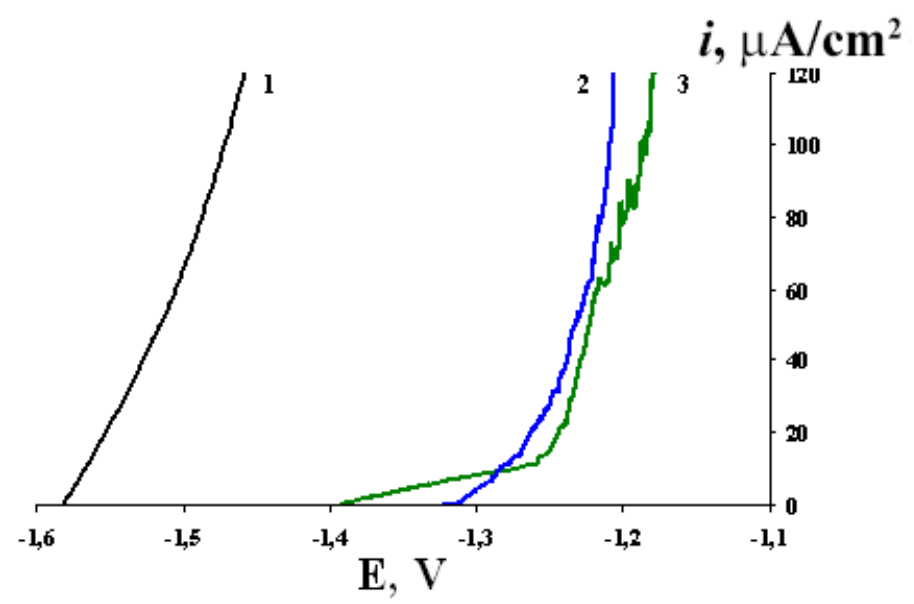

Figure 7. The anodic polarization curves of WE-43 magnesium alloy in $0.05 \mathrm{M} \mathrm{NaCl}$ without (1) and with addition of $0.01 \mathrm{M}$ sodium oleate (2) or SDOP (3).

On considering the adsorptive and passivating properties of acidic alkyl, aryl, dialkyl and diphenyl phosphates with respect to different metals in neutral solutions, it can be concluded that they can even be superior to higher carboxylate anions. It seems quite reasonable to continue searching for more efficient corrosion inhibitors of this class, including those for other metals and alloys, in the near future. For example, S. Tosatti et al. $[44,45]$ studied the monolayers formed in $48 \mathrm{~h}$ in aqueous solutions of ammonium salts of DDP and hydroxy-dodecyl phosphate (HDDP) on smooth and rough surfaces of Ti and $\mathrm{TiO}_{2}$. They found that on smooth surfaces the monolayers of DDP were densely packed, which provided hydrophobization of the surface (contact angle $\theta=110^{\circ}$ ), but the surface remained hydrophilic $\left(\theta=10-50^{\circ}\right)$ after HDDP adsorption. This is due to the difference in 
the terminal end groups of alkyls of the organophosphates studied: hydrophobic $-\mathrm{CH}_{3}$ in DDP and hydrophilic - OH in HDDP.

Of particular interest are the results obtained on rough Ti surfaces, as the field of its application covers medical implants and other devices in which chemical composition and topography of the surface are required. It turned out that the surface roughness changed surface wetting, with $\theta$ increasing to reach $150^{\circ}$, and the wetting hysteresis (the difference between the advancing and receding angles) also increased. This indicates the principal possibility to use alkylphosphates with a sufficiently long chain for superhydrophobization of the surface of various metals and to increase its corrosion resistance and other important properties.

Phytic acid, its salts and complexes with metals form a well-known group of organophosphates that was studied over the past decade on different metals in order to protect them from corrosion. They were studied not only as corrosion inhibitors or passivators forming ultrathin protective layers, but also as the main components of converting solutions.

Copper and its alloys. As already mentioned above, these studies began with a study of PhA and its salts as corrosion inhibitors of $\mathrm{Cu}$ and its alloys. H. Young et al. [46], using in situ surface enhanced Raman spectroscopy (SERS), revealed an interesting feature of adsorption on $\mathrm{Cu}$ from an aqueous solution of a sodium salt $\mathrm{Na}_{12} \mathrm{PhA}$, which at $C=$ $10 \mathrm{mmol} / \mathrm{l}$ increased the $\mathrm{pH}$ of double distilled water up to 11.3. Under these conditions, $\mathrm{Na}_{12} \mathrm{PhA}$ dissociates and in the first stage of its interaction with copper, the surface is chemically polished (self-cleaning process) due to the formation of soluble $\mathrm{Cu}_{x} \mathrm{PhA}$ complexes. This leads to removal of some oxide species of copper from the top layer of the roughened copper surface, and then $\mathrm{PhA}$ molecules are chemically adsorbed on the fresh surface to form ordered monolayers through two co-planar phosphate groups. According to the anodic polarization curves obtained in $0.1 \mathrm{M} \mathrm{KCl}$, the behavior of the $\mathrm{Cu}$ electrode reflects that it is protected to some extent by $\mathrm{PhA}$ monolayers, but the inhibition efficiency is rather small $(Z=41.2 \%)$. The authors explained this by co-adsorption of water, i.e., hydrophilicity of the surface, which is not very convincing since many effective corrosion inhibitors for $\mathrm{Cu}$ are rather hydrophilic $[29,30]$.

It seems more likely that the hydrophilic anions of $\mathrm{PhA}$ do not withstand competition in adsorption with $\mathrm{Cl}^{-}$anions, which were absent under conditions of formation of the protective film studied by Energy Dispersive X-ray Spectroscopy but were present in $0.1 \mathrm{M} \mathrm{KCl}$, i.e., in the solution used for electrochemical studies. In addition, the ability of $\mathrm{PhA}$ to form soluble complexes not only with $\mathrm{Cu}$ (I) but also with $\mathrm{Cu}$ (II) [47] can have a negative effect on the efficiency of metal protection.

Later, a high corrosion inhibition efficiency of sodium phytate toward $\mathrm{Cu}$ (about $90 \%$ ) was observed in $0.1 \mathrm{M} \mathrm{NaOH}$ [48]. It was shown that phytate promotes initial oxidation of copper to $\mathrm{Cu}^{+}$but strongly hindered subsequent oxidation to various corrosion products containing $\mathrm{Cu}^{2+}$. Thus, the integrity of the passive $\mathrm{Cu}_{2} \mathrm{O}$ layer was preserved and pitting corrosion was significantly suppressed by addition of $\mathrm{PhA}$ or its sodium salt. 
The adsorption of $\mathrm{PhA}$ on $\mathrm{Cu}$ was studied [49] using electrochemical polarization measurements, EIS and SERS. It was shown that the efficiency of the protective film of $\mathrm{PhA}$ on $\mathrm{Cu}$ in $3 \% \mathrm{NaCl}$ was $Z>80 \%$ at the optimum $C=0.1 \mathrm{mM}$ if the film was formed for $6 \mathrm{~h}$. From the polarization curves it follows that PhA acts as a cathodic inhibitor. In addition, studies have shown that $\mathrm{PhA}$ is adsorbed on the surface of $\mathrm{Cu}$ through $\mathrm{P}-\mathrm{O}$ groups. Assuming that the degree of filling with $\mathrm{PhA}$ molecules or anions, i.e., $\Theta$, is proportional to $Z(\%)$, the authors built an adsorption isotherm that was described by the Langmuir equation:

$$
\frac{C}{\Theta}=\frac{1}{B}+C
$$

The value of $\left(-\Delta G_{\mathrm{a}}^{0}\right)$ was calculated from the relationship $B=(1 / 55.5) \exp \left(-\Delta G_{\mathrm{a}}^{0} / R T\right)$ and amounted to $39.96 \mathrm{~kJ} / \mathrm{mol}$. It is close to $40 \mathrm{~kJ} / \mathrm{mol}$ which the authors believe to indicate the chemisorption of $\mathrm{PhA}$ on the $\mathrm{Cu}$ surface.

Attempts were made to use $\mathrm{PhA}$ salts, for example $\mathrm{PhACa}$, to create a protective layer on $\mathrm{Cu}$ and to assess its efficiency by EIS and by recording polarization curves of $\mathrm{Cu}$ in a $3 \% \mathrm{NaCl}$ solution [50]. It was concluded that $\mathrm{PhACa}$ was an effective corrosion inhibitor of mixed type $(Z=92.53 \%)$ that slows down the cathodic and anodic reactions on $\mathrm{Cu}$. The maximum $Z=92.53 \%$ is achieved when the $\mathrm{PhACa}$ concentration is $10^{-3} \mathrm{M}$ and the immersion time is $5 \mathrm{~h}$. Adsorption of PhACa on the $\mathrm{Cu}$ surface was estimated from EIS data and potentiodynamic polarization results under the assumption that $Z(\%)=\Theta \cdot 100$. Adsorption followed the Langmuir isotherm with $\left(-\Delta G_{\mathrm{a}}^{0}\right)=37.3 \mathrm{~kJ} / \mathrm{mol}$. In the authors' opinion, this value indicated chemisorption of PhACa. A SERS study elucidated that the formation of $\mathrm{PhACa}$ film occurs through $\mathrm{P}-\mathrm{O}$ and $\mathrm{P}=\mathrm{O}$ groups chemically attached to the copper surface.

The protective properties of $\mathrm{PhA}$ and its salts with respect to copper alloys were also studied. A self-assembled monolayer (SAM) of PhA formed in its $0.01 \mathrm{M}$ solution ( $\mathrm{pH}$ 1.78) on the surface of the $\mathrm{B} 30$ alloy $(65-70 \% \mathrm{Cu}, 29-32 \% \mathrm{Ni})$ was studied by electrochemical and photoelectrochemical methods in $3 \% \mathrm{NaCl}$ [51]. It has been shown that $\mathrm{PhA}$ can interact with the alloy to form complexes on its surface that slow down corrosion. The SAM changed the structure of the double electric layer and decreased its capacitance. The $\mathrm{B} 30$ electrode showed a $p$-type photoresponse, which came from a $\mathrm{Cu}_{2} \mathrm{O}$ layer on its surface. The photoresponse decreased greatly due to the SAM of PhA and the anticorrosion resistance was enhanced. The authors used polarization curves of the alloy obtained in solutions with various $C_{\mathrm{PhA}}$ to calculate the adsorption isotherm. They found $\mathrm{PhA}$ adsorption to follow the Langmuir isotherm with $\left(-\Delta G_{\mathrm{a}}^{0}\right) \sim 40 \mathrm{~kJ} / \mathrm{mol}$ and therefore concluded that chemisorption of PhA occurred.

High corrosion inhibition efficiency of sodium phytate toward brass was achieved in $0.1 \mathrm{M} \mathrm{NaOH}$ [52]. A thin-layered electrochemical cell with a corresponding light path length was fabricated. It was evaluated using cyclic voltammetry, UV spectroscopy, and 
scanning electron microscopy. Soluble ions, such as $\mathrm{Zn}(\mathrm{OH})_{4}^{2-}, \mathrm{Cu}(\mathrm{I}), \mathrm{Cu}(\mathrm{OH})_{4}^{2-}$ and other $\mathrm{Cu}(\mathrm{II})-\mathrm{O}$ complexes, were monitored in situ under potentiostatic and potentiodynamic conditions. It was shown that the efficiency of sodium phytate strongly depended on the concentration of $\mathrm{NaOH}$, reaching $~ 90 \%$ at the first cycle in $0.1 \mathrm{M} \mathrm{NaOH}$ and above $99 \%$ in the fourth cycle. In this case, a compact barrier layer of $\mathrm{Cu}_{2} \mathrm{O}$ nanoparticles can be formed instead of loose oxide microparticles elongated in the form of leaves that are formed in the absence of $\mathrm{Na}_{12} \mathrm{PhA}$. In addition, the inhibitor can suppress the formation of various complexes, not only of $\mathrm{Cu}^{2+}$ but also of $\mathrm{Zn}^{2+}$.

It seems interesting to use $\mathrm{PhA}$ anions as a corrosion inhibitor introduced into solution during the electrochemical synthesis of thin polypyrrole films. Since the electropolymerization of the monomer begins on passive $\mathrm{Cu}$, an aqueous solution with passivating properties is used to prevent the metal from corrosion [53]. It has long been known [54] that $\mathrm{PhA}$ and its salts can be used as primers on a metal before an organic coating is applied, which apparently improves its adhesion.

The protective properties of conducting polymer films obtained on $\mathrm{Cu}$ by electropolymerization in a $0.1 \mathrm{M}$ solution of $\mathrm{PhA}$ containing $0.5 \mathrm{M}$ pyrrole monomer with $\mathrm{pH} 6.0$ were studied in $3.5 \% \mathrm{NaCl}$ using EIS method. Analysis of impedance spectra led the authors to the conclusion that the equivalent circuit could be represented as [53]:

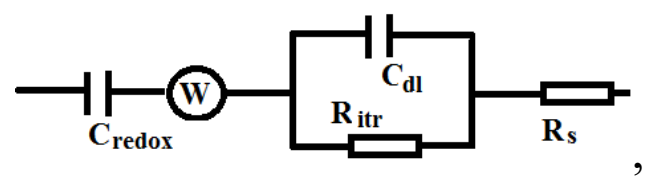

where $C_{\text {redox }}$ is the redox capacitance of the polypyrrole film, $C_{\mathrm{dl}}$ is the capacitance of the double electrical layer, $R_{\text {itr }}$ is the ionic transfer resistance, $R_{\mathrm{S}}$ is the solution resistance, and $\mathrm{W}$ is the Warburg impedance of diffusion processes in the film. In addition, the number of copper ions was determined in the solution of the electrode dissolved during exposure without and with a conductive coating of polypyrrole containing PhA. It was found that in the second case, the corrosion rate of copper was 19 times lower than in the first case.

Measurement of $\mathrm{Cu}$ corrosion potential $\left(E_{\mathrm{cor}}\right)$ in time has shown that its value remains much more positive for a long period $\left(\geq 800 \mathrm{~h}\right.$ ) than the $E_{\text {cor }}$ in the $3.5 \% \mathrm{NaCl}$ solution itself. Noticeable degradation of the protective coating begins after $\approx 750 \mathrm{~h}$ of the electrode exposure in the chloride solution. This is due to the loss of oxidizing properties of the polypyrrole film doped by $\mathrm{PhA}$-copper complexes. As a result of degradation, the value of $R_{\text {itr }}$ increases and $C_{\text {redox }}$ decreases.

Magnesium alloys. It is no exaggeration to state that in the past decade, the greatest attention to the protective properties of $\mathrm{PhA}$ and its salts was attracted to the problem of increasing the corrosion resistance of $\mathrm{Mg}$ and its alloys. They have a number of important properties that are useful for a wide range of applications in the automobile and machine building, aerospace industries, etc. Unfortunately, the low corrosion resistance of these alloys limits their extensive use in many fields. 
The peculiar structure of phytic acid has powerful capability of chelating with many metal ions [52]. If metal atoms or ions on the surface of $\mathrm{Mg}$ or its alloys react with active groups of $\mathrm{PhA}$ to form chelate compounds, they can precipitate on the surface to form a conversion coating (CC) that will improve the corrosion resistance of these alloys. It was this function of $\mathrm{PhA}$ for the anti-corrosion protection of $\mathrm{Mg}$ alloys that aroused the greatest interest of researchers. This is due to the fact that conventional conversion solutions contain $\mathrm{Cr}(\mathrm{VI})$, which is harmful to environment and has been restricted or forbidden for use in many countries.

In one of the first studies on the development of a conversion solution based on $\mathrm{PhA}$ and the CC properties on the AZ91D alloy (mass\%: 8.5 Al, 0.77 Zn, 0.25 Mn, 0.02 Si, Ni $\leq$ $0.001, \mathrm{Cu} \leq 0.002, \mathrm{Fe} \leq 0.004)$, the parameters were varied in the following ranges: $C_{\mathrm{PhA}}=$ $0.3-2.5 \%, \mathrm{pH} 1-9, t=25-80^{\circ} \mathrm{C}$, treatment time $10-180 \mathrm{~min}$ [21]. Samples with a $\mathrm{CC}$ were immersed for some time into a $3.5 \% \mathrm{NaCl}$ solution at $25^{\circ} \mathrm{C}$ to evaluate the corrosion effect through the rate of $\mathrm{H}_{2}$ evolution. It was found that the rates of $\mathrm{H}_{2}$ evolution were the lowest for the CCs formed in the treatment solutions with $\mathrm{pH} 3$ or 5 , which indicated that these CCs had better corrosion resistance. The reason might be that there was a "gentle" reaction between $\mathrm{Mg}$ and $\mathrm{PhA}$ at $\mathrm{pH} 3$ and 5, which was in favor of forming compact surface films. The corrosion resistance of the $\mathrm{Mg}$ alloy could be improved by treatment with a solution containing $1 \% \mathrm{PhA}$ at $60^{\circ} \mathrm{C}$ and $\mathrm{pH} 3-5$.

In the conversion solution with $\mathrm{pH} 1$, rapid $\mathrm{H}_{2}$ evolution interfered with the formation of a $\mathrm{CC}$ on the alloy. The $\mathrm{CC}$ did not cover its surface completely, which impaired its corrosion resistance. At $\mathrm{pH} \mathrm{9,} \mathrm{Mg}$ could react with water to form some oxide and hydrate. They were deposited on the surface of the $\mathrm{Mg}$ alloy together with the $\mathrm{PhA}$ complex to form a blended surface layer that was very loose and could not provide effective corrosion resistance.

To analyze the protective properties of the $\mathrm{CC}$ formed in a solution containing $\mathrm{PhA}$, the $E_{\text {cor }}$ values were determined and potentiodynamic polarization curves were measured on $\mathrm{Mg}$ alloy samples with different CCs. The $E_{\text {cor }}$ value changed from the starting value of -1.591 to the final $-1.311 \mathrm{~V}$ for the untreated magnesium alloy sample. It has the lowest $E_{\text {cor }}$ value, which indicated that untreated $\mathrm{Mg}$ was not stable in $3.5 \% \mathrm{NaCl}$ solution. For the sample containing chromate and phytate $\mathrm{CCs}$, the $E_{\text {cor }}$ value changed from -1.188 to $-1.172 \mathrm{~V}$ and from -1.320 to $-1.215 \mathrm{~V}$, respectively. This indicates that the stability of a sample with a phytate $\mathrm{CC}$ is lower than that of a sample with a chromate $\mathrm{CC}$, but better than that of a sample with an air-formed oxide film. The same conclusion is reached by the authors who analyzed the results of polarization measurements of the alloy in a chloride solution.

The effect of the PhA concentration on the formation of the CCs on the alloy AZ91D, their microstructure, chemical state and corrosion resistance was studied by measuring the gain in the sample mass, field emission scanning electron microscopy (FESEM), Fourier transform infrared spectroscopy (FTIR), potentiodynamic polarization and SEI, respectively [55]. It was shown that $C_{\mathrm{PhA}}=5 \mathrm{~g} / 1$ corresponds to the maximum weight gain 
and the $\mathrm{CC}$ formed in solution had the best corrosion resistance. The CCs formed at $C_{\mathrm{PhA}}=$ 1-5 g/l are uniform, but those formed in the solution with $20-50 \mathrm{~g} / 1 \mathrm{PhA}$ have some micro-cracks.

In another paper [23], the same authors studied the microstructure of phytate-based $\mathrm{CCs}$ on the same $\mathrm{Mg}$ alloy obtained in an aqueous solution containing $5 \mathrm{~g} / \mathrm{PhA}$ at $t=$ $20^{\circ} \mathrm{C}$. Using AFM and scanning electron microscopy (SEM), they found that the CC was of good quality and had no cracks. According to XPS and Auger electron spectroscopy (AES), the CC contains $\mathrm{Mg}, \mathrm{Al}, \mathrm{O}, \mathrm{P}$ and $\mathrm{C}$ as its main elements. The chemical state of the elements in the $\mathrm{CC}$ was also investigated by Fourier transform infrared spectroscopy (FTIR). Considering the compositions of the AZ91D alloy and PhA, it can also be concluded that the coating is the product of the reaction of $\mathrm{PhA}$ and magnesium alloy. Since the content of $\mathrm{Mg}$ and $\mathrm{Al}$ elements at a depth of $340 \mathrm{~nm}$ reaches the content of the substrate AZ91D, this indicates that the CC thickness is about $340 \mathrm{~nm}$. The results of anodic polarization of $\mathrm{AZ91D}$ alloy in $3.5 \% \mathrm{NaCl}$ solution indicate that phytate $\mathrm{CC}$ can improve the corrosion resistance of the alloy.

Fusheng Pan et al. [56] studied the effect of solution $\mathrm{pH}, C_{\mathrm{PhA}}$, and duration of CC formation on the surface of a similar alloy (AZ61, mass\%: $6.11 \mathrm{Al}, 1.09 \mathrm{Zn}, 0.23 \mathrm{Mn}$ ), as well as the microstructure and properties of the CC. They found that the optimal CC was formed after $20 \mathrm{~min}$ of immersion of the alloy sample in a $0.5 \mathrm{~g} / \mathrm{l} \mathrm{PhA}$ solution with $\mathrm{pH} 5$ due to precipitation of the $\mathrm{PhA}$ chelate with $\mathrm{Al}^{3+}$.

This somewhat unexpected conclusion about the nature of the $\mathrm{CC}$ was made based on the results of FTIR and energy dispersive X-ray spectroscopy. Interestingly, when the phytate $\mathrm{CC}$ on the AZ91D alloy, which contains $8.5 \% \mathrm{Al}$ was studied earlier, the main focus was on the interaction of $\mathrm{PhA}$ with $\mathrm{Mg}$. The $\mathrm{CC}$ obtained has an excellent adhesion not only to the alloy, but also to the outer layer with the paint coating, which makes it possible to use it as a primer.

The transparent $\mathrm{CC}$ obtained in $0.5-3 \mathrm{~min}$ in a slightly alkaline $(\mathrm{pH} 9 \pm 1) 20 \mathrm{~g} / 1 \mathrm{PhA}$ solution deserves attention [57]. Electron probe microanalysis (EPMA) of the CC showed that $\mathrm{PhA}$ was involved in its formation. The $\mathrm{P}$ element was considered as an indicator of the $\mathrm{PhA}$ molecule, for its content could hardly change during the analytical process. It turned out that the atomic ratio of $\mathrm{O}, \mathrm{C}$ and $\mathrm{P}$ elements in the $\mathrm{CC}$ was 13.7:5.03:1, while their ratio in the $\mathrm{PhA}$ molecule was $4: 1: 1$. It was concluded that apart from $\mathrm{PhA}$, an oxide or hydroxide was present in the $\mathrm{CC}$, which was also confirmed by IR spectroscopic studies of the CC. They revealed that the stains on the CC were mainly composed of $\mathrm{Mg}$ and $\mathrm{Al}$, which was caused by a nonuniformity of the alloy composition. The uniform distribution of $\mathrm{O}, \mathrm{P}$, and $\mathrm{C}$ on the entire surface showed that a compact $\mathrm{CC}$ was formed on the alloy.

In the SEM photographs, cracks were found on the surface of the sample after its treatment in a $\mathrm{PhA}$ solution with $\mathrm{pH}<8.06$. However, as the $\mathrm{pH}$ of the solution increases, the cracks decrease, but at the same time, if the $\mathrm{pH}$ is higher than 12.0, the $\mathrm{CC}$ can hardly be formed in a short time. That is why the authors recommended that $\mathrm{pH}$ be adjusted to values around 9.00-10.00 during the conversion treatment. Electrochemical tests showed 
that conversion treatment by a PhA solution enhanced the corrosion resistance of AZ31 alloy.

Such a search for an optimal conditions of CC formation in PhA solutions and studies of its properties were also carried out on pure $\mathrm{Mg}[58,59]$ and on other alloys [60-62]. For example, a phytate $\mathrm{CC}$ was formed by immersing $\mathrm{Mg}(99.9 \%)$ in an aqueous solution of $\mathrm{PhA}$ at room temperature for $3 \mathrm{~h}$. The treatment time was optimized to obtain a minimum corrosion current density. After the treatment, the samples were washed with deionized water and dried at room temperature. The microstructure and corrosion resistance properties of the phytate CCs obtained were improved after heat treatment carried out by heating at $95^{\circ} \mathrm{C}$ for $1 \mathrm{~h}$ in a vacuum. The highest impedance value for the heat treated sample confirmed that heat treatment increased its corrosion resistance properties.

One of the important areas in medicine is the improvement of non-toxic materials for cardiovascular stents, which are already in use and have saved many human lives. Magnesium and its alloys have many advantages over other biomaterials, but their low corrosion resistance requires serious enhancement. The CCs formed on $\mathrm{Mg}$ or its alloys in a non-toxic aqueous solution of $\mathrm{PhA}$ are promising means for solving this problem.

In [59], preliminary alkaline treatment of $\mathrm{Mg}(99.99 \%)$ was used to introduce $\mathrm{OH}$ groups on its surface, so that $\mathrm{PhA}$ molecules covalently bonded to it. After alkaline treatment, the samples were immersed for 20 min in a solution with $5.0 \mathrm{~g} / 1 \mathrm{of} \mathrm{PhA}, \mathrm{pH} 5$ and $60^{\circ} \mathrm{C}$. The covalently anchored $\mathrm{PhA}$ facilitates the subsequent precipitation of its complexes with magnesium ions released from the surface because of corrosion. The corrosion behavior and biodegradation of $\mathrm{Mg}$ modified with $\mathrm{PhA}$ were also studied and the hemolysis coefficient was determined in order to assess the practical possibilities of this biomaterial. It is shown that the phytate $\mathrm{CC}$ can be made denser and more homogeneous than the $\mathrm{CC}$ obtained by direct precipitation of $\mathrm{Mg}$ phytate. It shows significantly lower rates of corrosion and degradation in comparison not only with $\mathrm{Mg}$ without a coating, but also with a CC applied without prior alkaline modification. Primary bio-screening tests showed that $\mathrm{Mg}$ modified with $\mathrm{PhA}$ has clinically acceptable hemolysis ratios of less than $5.0 \%$, thus preserving the possibility of using it as a structural material for cardiovascular stents.

As early as in 1988, Stack et al. [60] showed that a biodegradable stent (BDS) can significantly reduce the in-stent restenosis rate. WE43 is one of the best-studied alloys of this kind [61]. Mg alloys are prominent among materials potentially suitable for BDS. It is not surprising that the possibility of formation of phytate $\mathrm{CC}$ on this alloy, its microstructure, biocompatibility and corrosion resistance were studied using modern physicochemical methods [62].

The hydrogen evolution and potentiodynamic polarization results show an improved corrosion resistance of PhA-treated WE43 alloy in simulated body fluid (SBF) solution compared with the untreated sample. According to the SEM and EDS results, it was found that different solutions formed a film with different P contents. Since P was an indicator of $\mathrm{PhA}$ only, the content of the latter in the CC was estimated from it. Samples treated with 
an acid $\mathrm{PhA}$ solution with $\mathrm{pH} 3$ and $\mathrm{pH} 5$ had a high $\mathrm{P}$ content that corresponds to a smaller coating with $\mathrm{PhA}$, although the surfaces have larger cracks compared to the groups obtained at $\mathrm{pH} 8$ and $\mathrm{pH} 10$. At the same time, it was determined that the corrosion rates of samples treated with $\mathrm{PhA}$ increased in the series: $\mathrm{pH} 5<\mathrm{pH} 3<\mathrm{pH} 8<\mathrm{pH} 10$. This also shows that the greater the Mg phytate content on the alloy surface, the higher its corrosion resistance in the SBF.

Evaluation of cytotoxicity showed that the biocompatibility of WE43 alloys treated with $\mathrm{PhA}$ is much better than that of the pure alloy. Since conversion solution with $\mathrm{pH} 5$ has better cell viability, it can be assumed that modified samples with a large amount of $\mathrm{PhAMg}$ complex will have better biocompatibility. The hemolysis evaluation results also showed that $\mathrm{CC}$ obtained in a solution with $\mathrm{pH} 5$ have the lowest hemolysis rate. This again proves that $\mathrm{PhA}$ has a good biocompatibility. Therefore, it was concluded [62] that treatment in a PhA solution is a promising method for increasing the corrosion resistance and biocompatibility of WE43 alloy.

Apparently, a phytate $\mathrm{CC}$ possesses a protective ability not only toward $\mathrm{Mg}-\mathrm{Al}$ alloys, since WE43 does not contain Al. A superlight Mg-Li alloy (mass\%: 11.0 Li, 3.0 Al, 0.5 rem.), which has excellent physical and mechanical properties, also contains a little Al. However, $\mathrm{Mg}$ and Li cause its low corrosion resistance, which limits the use of the alloy. According to [63], a uniform $\mathrm{CC}$ with a white flower-like deposit was formed on $\mathrm{Mg}-\mathrm{Li}$ alloy surface in an aqueous $\mathrm{PhA}$ solution. The $\mathrm{pH}$ value of the solution was the main factor affecting the formation of the phytate $\mathrm{CC}$. The optimum parameters of the conversion process were as follows: $C_{\mathrm{PhA}}=20 \mathrm{~g} / \mathrm{l}$, solution temperature $35^{\circ} \mathrm{C}$, and $\mathrm{pH} 6$, treatment time $10 \mathrm{~min}$. The $\mathrm{CC}$ mainly consisted of $\mathrm{Mg}, \mathrm{Al}, \mathrm{O}, \mathrm{P}$ and $\mathrm{C}$. Chelate compounds were formed by $\mathrm{PhA}$ with $\mathrm{Mg}^{2+}$ or $\mathrm{Al}^{3+}$. The $\mathrm{CC}$ increased the $E_{\text {cor }}$ and decreased the anodic current density and hydrogen evolution rate. Although direct corrosion tests of the alloy with phytate CC were not performed, the results of electrochemical measurements allow us to believe that the coating improves the corrosion resistance of the $\mathrm{Mg}-\mathrm{Li}$ alloy.

Despite a noticeable increase in the corrosion resistance of different $\mathrm{Mg}$ alloys with phytate CC, the possibility of its further enhancement is also studied. For example, in [64] the $\mathrm{Mg}$ alloy AZ31B (mass\%: $2.80 \mathrm{Al}, 0.80 \mathrm{Zn}, 0.38 \mathrm{Mn}, \mathrm{Si}<0.02, \mathrm{Cu} \leq 0.025, \mathrm{Fe} \leq 0.004$ ) was first treated for $40 \mathrm{~min}$ in a solution containing $4.0 \mathrm{~g} / 1 \mathrm{PhA}$ at $\mathrm{pH} 2$ and $t=60^{\circ} \mathrm{C}$. In the second stage, samples of the alloy with phytate $\mathrm{CC}$ were immersed for $30 \mathrm{~min}$ in a solution containing $0.06 \mathrm{M} \mathrm{Ce}\left(\mathrm{NO}_{3}\right)_{3}+4 \mathrm{ml} / 1 \mathrm{H}_{2} \mathrm{O}_{2}$ at $t=50^{\circ} \mathrm{C}$. The new composite coating has better uniformity than the phytate $\mathrm{CC}$ and it is composed of $\mathrm{O}, \mathrm{C}, \mathrm{P}, \mathrm{Mg}, \mathrm{Al}$ and $\mathrm{CeO}_{2}$. This sample was found to have the best corrosion resistance in $3.5 \% \mathrm{NaCl}$ not only in comparison with the untreated sample but also with samples with phytate or chromate CC. Similar results were obtained by other authors on pure $\mathrm{Mg}(99.95 \%)$ [21].

R.K. Gupta et al. [65] used stearic acid (SA) to reduce cracks in a phytate CC on $\mathrm{Mg}$. For this purpose, samples of $\mathrm{Mg}$ with such a coating $\sim 2.3 \mu \mathrm{m}$ thick were placed for $2 \mathrm{~h}$ in a $1.0 \mathrm{~g} / 1 \mathrm{SA}$ solution in ethanol at $80^{\circ} \mathrm{C}$. The microcracks in the phytate $\mathrm{CC}$ were filled with 
$\mathrm{SA}$, which prevented the penetration of corrosive ions from the solution to $\mathrm{Mg}$, and thereby reduced the corrosion rate. Potentiodynamic polarization of the electrode and EIS show that the coating treated with SA provides an effective protection against corrosion on $\mathrm{Mg}$ in a phosphate-chloride solution. Unfortunately, the authors did not study the hydrophobic effect of SA and did not perform direct corrosion tests, which somewhat reduces the value of their data.

One more possibility of using $\mathrm{PhA}$ to improve the protective properties of various coatings on $\mathrm{Mg}$ alloys should be noted. R.F. Zhang et al. [66] studied the effect of $\mathrm{PhA}$ at $C \leq 12 \mathrm{~g} / \mathrm{l}$ in a solution containing $10 \mathrm{~g} / 1 \mathrm{NaOH}$ on the regime of microarc oxidation of the AZ91HP alloy (mass\%: $8.93 \mathrm{Al}, 0.47 \mathrm{Zn}, 0.22 \mathrm{Mn}, 0.03 \mathrm{Si}, 0.002 \mathrm{Cu}, 0.001 \mathrm{Ni}, 0.001 \mathrm{Fe}$ ). They studied the composition and morphology of the CC formed using EDRS and SEM, and its protective properties were estimated from the results of polarization measurements on the oxidized alloy in $3.5 \% \mathrm{NaCl}$. It has been shown that with increasing $C_{\mathrm{PhA}}$, the solution conductivity decreased, and the breakdown voltage increased. The $\mathrm{CC}$ formed in a solution containing $8 \mathrm{~g} / \mathrm{l}$ was optimal in uniformity of distribution of pores and in protective properties. The content of $\mathrm{O}, \mathrm{C}$, and $\mathrm{P}$ in the $\mathrm{CC}$ confirms that it contains $\mathrm{PhA}$.

F. Tanga et al. [67] reported on the development of an ecologically pure PhA-based corrosion inhibitor placed into silica nanoparticles by layer-by-layer self-assembly with poly(allylamine-hydrochloride). According to EIS measurements, such nanoparticles evenly distributed in sol-gel films are able to provide a long-term protective effect in a $3.5 \% \mathrm{NaCl}$ solution. Similar nanoparticles were used [68] to increase the protective properties of the coating obtained by plasma electrolytic oxidation (PEO) of a $\mathrm{Mg}$ alloy (mass. \%: $9.53 \mathrm{Gd}, 1.45 \mathrm{Y}$ and $0.7 \mathrm{Zr}$ ) in a solution containing, g/l: $180 \mathrm{KOH}, 40 \mathrm{Na}_{3} \mathrm{PO}_{4}$ and $35 \mathrm{KF}$. After the PEO coating with a thickness of $20 \pm 1 \mu \mathrm{m}$ was obtained, two layers were applied onto it. The first one contained nanoparticles with $\mathrm{PhA}$ (layer thickness 400 $600 \mathrm{~nm}$ ), and the second one was a fluorocarbon paint $10 \pm 1 \mu \mathrm{m}$ thick. The new composite film called PSPF showed enhanced barrier properties and can be used to provide reliable protection against corrosion. In addition, the strong adhesive properties of the PSPF film create good prospects of its long-term use in corrosive neutral chloride media.

Other metals and alloys are much less thoroughly investigated as an object of protection from corrosion using $\mathrm{PhA}$. In the above-mentioned work [67], nanocontainers containing $\mathrm{PhA}$ were obtained by "layer-by-layer" deposition including both a polyelectrolyte and a corrosion inhibitor. The hybrid film was synthesized by a controlled sol-gel route. For this, two different sols were combined to obtain a final hybrid sol-gel solution, which was finally applied to a plate of $16 \mathrm{Mn}$ low-alloy structural steel. To study the protective hybrid sol-gel film doped with $\mathrm{PhA}, 3$ types of films were prepared: (a) a film based on $\mathrm{SiO}_{x} / \mathrm{ZrO}_{x}$; (b) film (a) containing nano-containers with $\mathrm{PhA}$; (c) film (a) containing nanocontainers with BTA. From the results of the measurement of EIS in 3.5\% $\mathrm{NaCl}$ the authors concluded that the hybrid sol-gel film (b) has excellent stability and anticorrosive action. 
As mentioned above, the protective properties with respect to $\mathrm{Mg}$ are enhanced by a combination of $\mathrm{PhA}$ with $\mathrm{Ce}^{3+}$ [64]. This approach was used even earlier in the passivation of galvanized steel [69], although it was known that its separate passivation with a solution of $\mathrm{Ce}^{3+}$ or PhA was inferior in efficiency to chromate treatment. The authors confirmed that the use of a combined solution of these inhibitors increases the protection of galvanized steel, which was evaluated by the dropping method $\left(5 \% \mathrm{CuSO}_{4}\right)$, by corrosion rates determined from the mass loss of samples for $96 \mathrm{~h}$ in a solution of $0.5 \mathrm{M} \mathrm{NaCl}+$ $0.005 \mathrm{M} \mathrm{H}_{2} \mathrm{SO}_{4}$, and by electrochemical studies (polarization measurements and EIS).

Later the same authors [70] using the dropping and immersion mass loss tests found that samples passivated with a combined molybdate- $\mathrm{PhA}$ solution $\left(20 \mathrm{~g} / 1 \mathrm{Na}_{2} \mathrm{MO}_{4} ; 20 \mathrm{~g} / \mathrm{l}\right.$ $\mathrm{PhA} ; 1 \mathrm{~g} / 1 \mathrm{NaNO}_{2} ; 3 \mathrm{ml} / 163 \% \mathrm{HNO}_{3} ; 0.2 \mathrm{ml} / 1 \mathrm{98 \%} \mathrm{H}_{2} \mathrm{SO}_{4}$ ) showed better corrosion resistance than samples treated separately by molybdate or PhA. The electrochemical behaviour of the passivated samples was studied using potentiodynamic polarization and EIS in $0.5 \mathrm{M} \mathrm{NaCl}$ solution and showed $i_{\text {cor }}=4.95 \cdot 10^{-5} ; 5.10 \cdot 10^{-5}$ and $1.19 \cdot 10^{-5} \mathrm{~A} \cdot \mathrm{cm}^{-2}$, respectively. EIS also indicated that molybdate-phytic passivated samples exhibited better corrosion resistance.

When galvanized steel was treated in $\mathrm{PhA}$ solutions, dissolution of zinc occurred to form $\mathrm{Zn}^{2+}$, some active groups of $\mathrm{PhA}$ formed complexes with them and are adsorbed on the surface. Non-polar groups in PhA form a shielding layer on the sample to form a compact CC. Molybdate can be reduced to low valence oxides on the surface. These newly formed oxides may be entrapped in the conversion film. SEM observation identified that some oxide particles exist in the $\mathrm{CC}$, which are different from those observed in a purely molybdate film. Under this condition, it is assumed that the molybdate-phytate conversion film provides a more compact barrier on the surface, resulting in better corrosion resistance than that of single molybdate or PhA treatments.

In [71], the CCs formed on galvanized steel after preliminary immersing the samples for $10 \mathrm{~s}$ in an aqueous solution of $0.05 \mathrm{M} \mathrm{H}_{2} \mathrm{SO}_{4}+0.5 \% \mathrm{H}_{2} \mathrm{O}_{2}$, then washed with distilled water and ethanol and dried in a hot air stream were studied. After that, the samples were immersed in a hot alkaline solution $\left(50^{\circ} \mathrm{C}\right)$ for $5 \mathrm{~min}$, washed with water, and the first operation was repeated. Samples prepared in this way were treated in different converting solutions at $t=45^{\circ} \mathrm{C}$ in one or two stages. These solutions contained (mM): $0.5 \mathrm{PhA}$; $0.5 \mathrm{PhA}+1.0 \mathrm{MnSO}_{4} ; 1.0$ 2,3-dimercapto-1-propanol (DMP); 1.0 dithio-oxamide (DTOA); 0.5 diethylene triamine pentamethane phosphonic acid (DETAPMPA), and 0.5 DETAPMPA $+1.0 \mathrm{Cr}\left(\mathrm{NO}_{3}\right)_{3}$. The $\mathrm{pH}$ of the PhA and DETAPMPA solutions was adjusted to 4.0 by adding $\mathrm{KOH}$. Aqueous solutions of DMP and DOTA were prepared with addition of $5 \%$ ethanol and $n$-propanol, respectively.

The protective properties of the CCs were estimated from the results of polarization measurements and SEI obtained in $0.5 \mathrm{M} \mathrm{NaCl}$. Most of the samples with $\mathrm{CC}$ pretreated only in an $\mathrm{H}_{2} \mathrm{SO}_{4}+\mathrm{H}_{2} \mathrm{O}_{2}$ solution had higher protection efficiencies $(Z \%)$ than the samples pretreated both in the same solution and in the alkaline solution. Modification of the phytate or phytate-manganese $\mathrm{CC}$ was carried out by treatment for $60 \mathrm{~s}$ in a DMP or 
DTOA solution. According to $i_{\text {cor }}$ data calculated from polarization curves, the value of $Z$ for the CCs decreased in the series: $\mathrm{PhA}+\mathrm{MnSO}_{4}$, modification by DTOA (97.9\%) > $\mathrm{PhA}$, modification by DMP (97\%); DMP (96.9\%) $>\mathrm{PhA}+\mathrm{MnSO}_{4}$, modification by DMP $(94.5 \%)>\mathrm{PhA}$, modification by DTOA $(89 \%)>\mathrm{PhA}+\mathrm{MnSO}_{4}(86.8 \%)>$ DTOA $(84.2 \%)$ $>\operatorname{PhA}(56.4)>\operatorname{DETAPMP}(52.5 \%)>\operatorname{DETAPMP}+1.0 \mathrm{Cr}\left(\mathrm{NO}_{3}\right)_{3}(43.8 \%)$.

The EIS results showed a slightly different efficiency of the passivation treatment: $\mathrm{PhA}+\mathrm{MnSO}_{4}$, modification by DMP (97.7\%) $>\mathrm{PhA}+\mathrm{MnSO}_{4}$, modification by DTOA $(95.3 \%)>$ DMP $(95.0 \%)>$ PhA, modification by DTOA $(90.8 \%)>$ DTOA $(85.9 \%)>$ PhA $(18.0 \%)$. It is easy to see that the efficiency of the $\mathrm{PhA}$ itself in this estimation is 3 times lower, but it is indisputable that the modification of the phytate $\mathrm{CC}$, especially of that formed in the presence of $\mathrm{Mn}^{2+}$, significantly enhances the protection of galvanized steel.

In [72], the effect of the solution $\mathrm{pH}$ on the mode of binding between $\mathrm{PhA}$ and the $\mathrm{Fe}$ surface was studied. In was found that $\mathrm{PhA}$ can affect the corrosion behavior of $\mathrm{Fe}$ in different ways. It was found that $\mathrm{PhA}$ is adsorbed on the Fe surface from acidic solutions mainly as undissociated molecules and the inhibition efficiency reaches a maximum at $1.0 \cdot 10^{-4} \mathrm{M}$ PhA. According to polarization and EIS data, its adsorption obeys the Langmuir isotherm with $\left(-\Delta G_{\mathrm{a}}^{0}\right)=42.46 \mathrm{~kJ} / \mathrm{mol}$. They concluded that $\mathrm{PhA}$ molecules are chemisorbed on the Fe surface and are bound to it through the oxygen atoms of the phosphate groups. Under neutral solutions, $\mathrm{PhA}$ anions show strong complexing ability towards $\mathrm{Fe}$ (II) ions produced during anodic dissolution, and the resulting chelates can be deposited on the surface of the Fe electrode, leading to the formation of protective barrier layers. In this case, phytate works as a film former for CC.

Although PhA has been long attracting the attention of researchers as a means for the protection of light alloys against corrosion, this applies primarily to $\mathrm{Mg}$ alloys. However, apparently, in [73] the first attempt was made to develop a protective $\mathrm{CC}$ on Al alloy AA2024-T3 (mass\%: $4.54 \mathrm{Cu}, 1.51 \mathrm{Mg}, 0.63 \mathrm{Mn}, 0.17 \mathrm{Fe}, 0.06 \mathrm{Si}, 0.08 \mathrm{Zn}$ ) based on PhA. The CC was obtained at room temperature by dipping samples of the alloy for 30 minutes in a $0.05 \mathrm{M}$ PhA solution with $\mathrm{pH} 1.37$, but it was increased from 2.0 to 6.5 by addition of $\mathrm{NaOH}$. The samples were then rinsed for 2 minutes with deionized water and dried for $12 \mathrm{~h}$ in air. The results from SEM images and EDS analysis show that the PhA CCs formed at pH 5 and 6 on 2024-T3 Al alloy were better than those formed at other $\mathrm{pH}$ values. For the solutions with $\mathrm{pH} 5$ and 6 , the thickness of the PhA CC exceeded that of the CCs formed in solutions with $\mathrm{pH}<5$. The film formed at $\mathrm{pH} 5$ was more compact and uniform than that formed at $\mathrm{pH}$. The thickness of the phytate $\mathrm{CC}$ on the plateau of its $\mathrm{pH}$ dependence (5-6) reached $2 \mu \mathrm{m}$, but cracks or caves were found along or inside the film formed at $\mathrm{pH} 6$.

Analysis of the polarization curves of the alloy obtained in $0.05 \mathrm{M} \mathrm{NaCl}$, the CCs formed in PhA solutions at $\mathrm{pH} 3.5-5.0$ have good protective properties $(Z=83.3-87.7 \%)$. IR analysis showed that the phosphate groups in $\mathrm{PhA}$ can form chelates with $\mathrm{Al}^{3+}$, precipitation of which allows a protective CC to be formed on AA2024-T3 alloy. It may be stated that studies and improvements of $\mathrm{PhA}$, its salts and formulations based on them as environmentally friendly means of protecting $\mathrm{Al}$ alloys against corrosion will continue. 
Of particular interest is the layer-by-layer treatment of a surface to be protected for the formation of thin protective layers on metals from aqueous solutions of mixtures of corrosion inhibitors belonging to different classes of organic compounds. Its results can significantly exceed the efficiency of treatment in a solution of a mixture of the same corrosion inhibitors. Moreover, one does not need to worry about the stability of the mixture solution since its components may be incompatible in it.

In this context, identification of the features of the adsorption of corrosion inhibitors and their mixtures is among the most important scientific problems. Examples of such studies were discussed above and in the earlier parts of this review [29, 30]. Interesting results were also obtained with $\mathrm{PhANa}$ in [20], where its competitive adsorption with 4methyl-4H-1,2,4-triazole-3-thiol (4-MTT) on Ag surface was studied using electrochemical measurements and SERS. It was shown that the adsorption monolayers of 4-MTT or PhANa on Ag are stable, and due to the compactness and uniformity of the composition they improve the corrosion resistance of the surface in $0.10 \mathrm{M} \mathrm{KCl}$. The effect of PhA adsorption on the structure of 4-MTT monolayers was weaker than the effect of 4MTT adsorption on the Ag surface with PhA monolayers. Joint adsorption of 4-MTT and $\mathrm{PhA}$ on $\mathrm{Ag}$ was observed from a solution containing both corrosion inhibitors, but their mixed coating was unstable and did not provide corrosion protection.

\section{Conclusions}

1. Acid organic esters of $\mathrm{H}_{3} \mathrm{PO}_{4}$ and their salts can effectively facilitate the passivation of metals and its stabilization in corrosive environments (aqueous solutions with $\mathrm{pH} \geq 5.0$ and corrosive atmospheres). For strong adsorption of their anions on different metals from aqueous solutions, they must contain hydrocarbon radicals that impart them hydrophobic properties characterized by $\log D>0$. At the same time, the corrosion inhibitor should have moderate solubility in water.

2. The optimal range of $\log D$ values (at $\mathrm{pH} 7.4$ ) is significantly different for mono- and dialkyl phosphates. In the first case, DDP, one of the best-studied corrosion inhibitors, which is an effective passivator for some metals, is even slightly hydrophilic $(\log D=$ -0.07 ). It is likely that increasing the alkyl length from $\mathrm{C}_{12}$ to $\mathrm{C}_{16}$ (hexadecylphosphoric acid, $\log D=2.06$ ) can preserve its solubility in water, that is sufficient for even more effective protection of metals. Among dialkyl phosphates, SDOP was most studied as a passivating agent. It is characterized by $\log D=2.95$ and high values of $\left(-\Delta G_{\mathrm{a}}^{0}\right)$ on reduced (at $E=-0.65 \mathrm{~V}$ ) and oxidized (at $0.2 \mathrm{~V}$ ) St3 surface $(32.06$ and $26.4 \mathrm{~kJ} / \mathrm{mol}$, respectively), on oxidized D16 alloy at $E=-0.30 \mathrm{~V}$ and on technically pure $\mathrm{Mg}(33.8$ and $50.2 \mathrm{~kJ} / \mathrm{mol}$, respectively). This passivator has a noticeable versatility of action and, at least, is not inferior in efficiency to toxic chromate. However, increasing the protection of metals from corrosion by increasing the length of alkyl chains in such organophosphates, even up to $\mathrm{C}_{10}$, increases $\log D$ to 5.08 and may not result in a positive effect due to a decrease in the solubility of the corrosion inhibitor in water. 
Increasing the passivating properties of both types of organophosphates can be achieved using their salts with cerium or other REM, mixtures with certain azoles and silanes.

3. The polybasic and very hydrophilic phytic acid (PhA, $\log P=-8.47, \log D \sim-24.0$ at $\mathrm{pH}$ 7.4) and its salts are attractive due to ecological safety and high reactivity. However, the mechanism of metal protection by these compounds differs significantly from the other organophosphates considered in the review. Because of its high hydrophilicity, $\mathrm{PhA}$ forms many water-soluble complexes, thus activating the surface in a peculiar way, and can then form ordered chemisorption layers that are bound to it by two coplanar phosphate groups. It is not surprising that $\mathrm{PhA}$ and its salts are capable of forming protective phytate $\mathrm{CCs}$ on various metals $(\mathrm{Cu}, \mathrm{Mg}, \mathrm{Al}, \mathrm{Zn}$, galvanized steel) and alloys.

4. Of the greatest interest are phytate $\mathrm{CCs}$ for $\mathrm{Mg}$ and its alloys, which may become safe substitutes for toxic chromate CCs in technology and have prospects for use in medicine as a structural material for cardiovascular stents. The methods suggested for increasing the protective properties of phytate $\mathrm{CCs}$ by further treatment them in a solution of a cerium salt or stearic acid, as well as the use of PhA in PEO coatings and sol-gel protective films, are worthy of attention.

5. Good prospects also exist for the use of phytate CCs on galvanized steels and aluminum alloys.

\section{Acknowledgements}

This work was supported by RFBR grant no. 16-03-00199 "Surface modification of Al, $\mathrm{Mg}$ and their alloys by nanolayers of organic corrosion inhibitors."

\section{References}

1. A.V. Fokin, M.V. Pospelov and Levichev A.N., "Oil-soluble corrosion inhibitors. The mechanism of action and applied formulations," in: Results of science and technology, Series: Corrosion and corrosion protection, 1984, Moscow, VINITI, Vol. 10, pp. 3-77 (in Russian).

2. Y.X. Chen, W.M. Liu, C.F. Ye, L.G. Yu and S.K. Qi, "Preparation and characterization of self-assembled alkanephosphate monolayers on glass substrate coated with nano$\mathrm{TiO}_{2}$ thin film," Mater. Res. Bull., 2001, 36, no. 15, 2605-2612.

3. Yu.I. Kuznetsov, Organic Inhibitors of Corrosion of Metals, New York, Plenum Press, 1996, 283 pp.

4. N.M. Dyatlova, V.Ya. Temkina and K.I. Popov, Kompleksony $i$ Kompleksonaty Metallov (Complexones and Complexonates), 1988, Moscow, Khimiya, 544 pp. (in Russian).

5. Yu.I. Kuznetsov, N.P. Andreeva and G.Yu. Kazanskaya, "On the Inhibition Effect of Dialkyl Phosphates in the Depassivation of Metals", Prot. Met., 2000. 36, no. 4, 351355. 
6. D.M. Spori, N.V. Venkataraman, S.G.P. Tosatti, F. Durmaz, N.D. Spencer and S. Zurcher, "Influence of Alkyl Chain Length on Phosphate Self-Assembled Monolayers," Langmuir, 2007, 23, 8053-8060.

7. S.V. Oleynik, Yu.A. Kuzenkov, N.P. Andreeva and Yu.I. Kuznetsov, Korroz.: mater., zashch., 2008, no. 3, 29-34 (in Russian).

8. P.M. Karlsson, A.E.C. Palmqvist and K. Holmberg, "Adsorption of sodium dodecyl sulfate and sodium dodecyl phosphate on aluminum, studied by QCM-D, XPS, and AAS," Langmuir, 2008, 24, 13414.

9. P.M. Karlsson, M.W. Anderson and A.E.C. Palmqvist, "Adsorption of sodium dodecyl sulfate and sodium dodecyl phosphate at the surface of aluminium oxide studied with AFM," Corros. Sci., 2010, 52, 1103-1105.

10. A.A. Chirkunov, A.S. Gorbachev, Yu.I. Kuznetsov and N.P. Andreeva, "Adsorption of Dioctyl Phosphate and Inhibition of Dissolution of Low-Carbon Steel," Prot. Met. Phys. Chem. Surf., 2013, 49, no. 7, 854-859. doi: 10.1134/S2070205113070058

11. S.J. Garcia, T.A. Markley, J.M.C. Mol and A.E. Hughes, "Unravelling the corrosion inhibition mechanisms of bi-functional inhibitors by EIS and SEM-EDS," Corros. Sci., 2013, 69, 346-358.

12. Yu.I. Kuznetsov, A.M. Semiletov and A.A. Chirkunov, "Inhibition of magnesium corrosion by triazoles," Int. J. Corros. Scale Inhib., 2016, 5, no. 1, 31-49. doi: http://dx.doi.org/10.17675/2305-6894-2016-5-1-3

13. N.P. Andreeva, Yu.I. Kuznetsov, A.M. Semiletov and A.A. Chirkunov, Korroz.: mater., zashch., 2017, no. 2, 41-48.

14. Yu.I. Kuznetsov, "Progress in Inhibition of Metal Corrosion and Modification of Safety Nanolayers on Metals," Prot. Met. Phys. Chem. Surf., 2011, 47, no. 7, 821-829. doi: $10.1134 /$ S2070205111070100

15. L.F. Johnson and M.E. Tate, "Structure of phytic acids," Canadian J. Chem., 1969, 47, no. $1,63-73$.

16. T. Notoya, V. Otieno-Alegot and D.P. Schweinsberg, "The corrosion and polarization behaviour of copper in domestic water in the presence of $\mathrm{Ca}, \mathrm{Mg}$ and Na-salts of phytic acid," Corros. Sci., 1995, 37, no. 1. 55-65.

17. T. Notoya, J. Japan Copper and Brass Research Association, 1986, 24, 21.

18. F. Cao, J. Wei, J. Dong and W. Ke, "The corrosion inhibition effect of phytic acid on 20SiMn steel in simulated carbonated concrete pore solution," Corros. Sci., 2015, 100, $365-376$.

19. G.M. Liu, L. Yang, F. Ym, J.H. Tian, S.W. Duo and N. Du, "Cerium-phytic acid passivation treatment on galvanized steel," Key Eng. Mater., 2008. 373-374, 228-231.

20. G.M. Liu, L. Yang, F.Y. Sun, W. Song, X. Zhu, Na Wang, Y. Wang, Y.C. Pan and Z. Zhang, "Competitive Adsorption of 4-Methyl-4H-1,2,4-triazole-3-thiol and Na Salt of Phytic Acid on a Silver Surface: Raman Spectral and Electrochemical Observations," J. Phys. Chem. C, 2009, 113, 9748-9754. 
21. L. Jianrui, G. Yina and H. Weidong, "Phytic Acid Conversion on Magnesium Surface Treatment with Cerium Chloride Solution," Prot. Met. Phys. Chem. Surf., 2012, 48, no. 2, 233-237.

22. L. Jianrui, G. Yina and H. Weidong, "Study on the corrosion resistance of phytic acid conversion coating for magnesium alloys," Surf. Coat. Technol., 2006, 201, 15361541.

23. X. Cui, Y. Li, Q. Li, G. Jin, M. Ding and F. Wan, "Influence of phytic acid concentration on performance of phytic acid conversion coatings on the AZ91D magnesium alloy," Mater. Chem. Phys., 2008, 111, 503-507.

24. E. Papirer, E. Walter, A. Vidal and B. Siffert, "Adsorption of Stearic Acid and Diethylhexyl Phosphate on Magnetic Metallic Iron Pigments: Electrical Surface Charging and Adsorption Competition," J. Colloid Interface Sci., 1997, 187, 529-538.

25. A.N. Frumkin, V.S. Bogotskii, Z.A. Iofa and D.N. Kabanov, Kinetics of Electrode Processes, 1952, Moscow State University, Moscow, 319 pp. (in Russian). Translated into English: Springfield, 1967. http://albus.fenk.wur.nl/ biesheuvel/Frumkin.html

26. A.N. Frumkin, Potentsialy Nulevogo Zaryada (Zero Charge Potentials), 1982, Nauka, Moscow, 260 pp. (in Russian).

27. C. Hansch and A. Leo, Correlation Analysis in Chemistry and Biology, 1981, New York, J.Wiley.

28. R.A. Scherrer and S.M. Howard, "Use of distribution coefficients in quantitative structure-activity relationships," J. Med. Chem., 1977, 20, no. 1, 53-58.

29. Yu.I. Kuznetsov, "Organic corrosion inhibitors: Where are we now? A review. Part I," Int. J. Corros. Scale Inhib., 2015, 4, no. 4, 284-310. doi: 10.17675/2305-6894-2015-4$\underline{4-1}$

30. Yu.I. Kuznetsov, "Organic corrosion inhibitors: Where are we now? A review. Part II. Passivation and the role of chemical structure of carboxylates," Int. J. Corros. Scale Inhib., 2016. 5, no 4, 282-318. doi: 10.17675/2305-6894-2016-5-4-1

31. Yu.I. Kuznetsov, Ya.G. Bober, N.P. Andreeva and L.P. Kazansky, "On passivation of iron by anions of sodium mephenaminate, fluphenaminate and their compositions with sodium oleate," The European corrosion congress "EUROCORR-2008", Edinburgh, UK, CD with full text of papers, p. 1223.

32. V.S. Siniavskyi, V.D. Val'kov and V.D. Kalinin, Korrozyia i zashchita alyuminievykh splavov (Corrosion and protection of aluminum alloys), 1986, Moscow, Metallurgiya, 368 pp. (in Russian).

33. P.M. Karlsson, M.W. Anderson and A.E.C. Palmqvist, "Surface modification for aluminium pigment inhibition," Adv. Colloid Interface Sci., 2006, 128-130, 121-134.

34. P.M. Karlsson, A. Baeza, M.W. Anderson and A.E.C. Palmqvist, "Surfactant inhibition of aluminium pigments for waterborne printing inks," Corros. Sci., 2008, 50, 22822287. 
35. P.M. Karlsson, B.R. Postmus and A.E.C. Palmqvist, "Dissolution and Protection of Aluminium Oxide in Corrosive Aqueous Media - An Ellipsometry and Reflectometry Study," J. Dispersion Sci. Technol., 2009, 30, 949-953.

36. M. Forsyth, M. Seter, B. Hinton, G. Deacon and P. Junk, "New 'Green' Corrosion Inhibitors Based on Rare Earth Compounds," Austr. J. Chem., 2011, 64, 812-819.

37. D. Ho, N. Brack, J. Scully, T.A. Markley, M. Forsyth and B.R.W. Hinton, "Cerium Dibutylphosphate as a Corrosion Inhibitor for AA2024-T3 Aluminum Alloys," $J$. Electrochem. Soc., 2006, 153, no. 9, B392. doi: 10.1149/1.2217260

38. T.A. Markley, M. Forsyth and A.E. Hughes, "Corrosion protection of AA2024-T3 using rare earth diphenyl phosphates," Electrochim. Acta, 2007, 52, no. 12, 40244031.

39. M. Forsyth, T.A. Markley, D. Ho, G.B. Deacon, P.C. Junk, B.R.W. Hinton and A. Hughes, "Inhibition of Corrosion on AA2024-T3 by New Environmentally Friendly Rare Earth Organophosphate Compounds," Corrosion, 2008, 64, no. 3, 191. doi: $10.5006 / 1.3278465$

40. S.J. Garcia, T.A. Markley, J.M.C. Mol and A.E. Hughes, "Unravelling the corrosion inhibition mechanisms of bi-functional inhibitors by EIS and SEM-EDS," Corros. Sci., 2013, 69, 346-358.

41. A.M. Semiletov, A.A. Chirkunov, Yu.I. Kuznetsov and L.P. Kazansky, "Anti-corrosion protection of magnesium by 5-chlorobenzotriazole and a formulation of its basis," Korroz.: mater., zashch., 2015, no. 11, 26-35 (in Russian).

42. A.A. Chirkunov and S.N. Gusev. "Inhibition of dissolution of magnesium alloy Electron WE43 by anion-active compounds," Korroz.: mater., zashch., 2016, no. 6, 37-41 (in Russian).

43. S.N. Gusev, A.A. Chirkunov and G.V. Red'kina, "Effect of Borate Buffer Solution and $\mathrm{NaCl}$ Concentration on the Anodic Behavior of a Magnesium Alloy Electron WE43 in the Presence of Inhibitors," Korroz.: mater., zashch., 2016, no. 6, 37-41 (in Russian).

44. S. Tosatti, R. Michel, M. Textor and N.D. Spencer, "Self-Assembled Monolayers of Dodecyl and Hydroxy-dodecyl Phosphates on Both Smooth and Rough Titanium and Titanium Oxide Surfaces," Langmuir, 2002, 18, 3537-3548.

45. M. Zwahlen, S. Tosatti, M. Textor and G. Hahner, "Orientation in Methyl- and Hydroxyl-Terminated Self-Assembled Alkanephosphate Monolayers on Titanium Oxide Surfaces Investigated with Soft X-ray Adsorption," Langmuir, 2002, 18, 39573962.

46. H. Yang, Yu Yang, Y. Yang, H. Liu, Z. Zhang, G. Shen and R. Yu, "Formation of inositol hexaphosphate monolayers at the copper surface from a Na-salt of phytic acid solution studied by in situ surface enhanced Raman scattering spectroscopy, Raman mapping and polarization measurement," Anal. Chim. Acta, 2005, 458, 159-165.

47. V. Ermanno, M. Stefano, C. Tonino, M. Osvaldo, F. Cecilia and M. Carla, "Complex formation between phitic acid and divalent metals ions: a solution equilibria and solid state investigation," Anal. Bioanal. Chem., 2002, 374, 173-178. 
48. Y.-H. Wang and J.-B. He, "Corrosion inhibition of copper by sodium phytate in $\mathrm{NaOH}$ solution: Cyclic voltabsorptometry for in situ monitoring of soluble corrosion products," Electrochim. Acta, 2012, 68, 45-51.

49. S. Shen, X. Guo, P. Song, Y.-C. Pan, H. Wang, Y. Wen and H.-F. Yang, "Phytic acid adsorption on the copper surface: Observation of electrochemistry and Raman spectroscopy," Appl. Surf. Sci., 2013, 276, 167-173.

50. C. Li, X. Guo, S. Shen, P. Song, T. Xu, Y. Wen and H.-F. Yang, "Adsorption and corrosion inhibition of phytic acid calcium on the copper surface in $3 \mathrm{wt} \% \mathrm{NaCl}$ solution," Corros. Sci., 2014, 83, 147-154.

51. C. Hao, R.-H. Yin, Z.-Y. Wana, Q.-J. Xu and G.-D. Zhou, "Electrochemical and photoelectrochemical study of the self-assembled monolayer phytic acid on cupronickel B30," Corros. Sci., 2008, 50, 3527-3533.

52. Y. Li, J.-B. He, M. Zhang and X.-L. He, "Corrosion inhibition effect of sodium phytate on brass in $\mathrm{NaOH}$ media. Potential-resolved formation of soluble corrosion products," Corros. Sci., 2013, 74, 116-122.

53. Y. Lei, N. Sheng, A. Hyono, M. Ueda and T. Ohtsuka, "Electrochemical synthesis of polypyrrole films on copper from phytic solution for corrosion protection," Corros. Sci., 2013, 76, 302-309.

54. E. Graf, "Applications of phytic acid,” J. Am. Oil Chem. Soc., 1983, 60, 1861-1867.

55. X. Cui, Q. Li, Y. Li, F. Wang, G. Jin and M. Ding, "Microstructure and corrosion resistance of phytic acid conversion coatings for magnesium alloy," Appl. Surf. Sci., 2008, 255, 2098-2103.

56. F. Pan, X. Yang and D. Zhang, "Chemical nature of phytic acid conversion coating on AZ61 magnesium alloy," Appl. Surf. Sci., 2009, 255, 8363-8371.

57. C.H. Liang, R.F. Zheng, N.B. Huang and L.S. Xu, "Conversion coating treatment for AZ31 magnesium alloys by a phytic acid bath," J. Appl. Electrochem., 2009, 39, 18571862.

58. R.K. Gupta, K. Mensah-Darkwa and D. Kumar, "Effect of Post Heat Treatment on Corrosion Resistance of Phytic Acid Conversion Coated Magnesium," J. Mater. Sci. Technol., 2013, 29, no. 2, 180-186.

59. Y. Chen, G. Wan, J. Wang, S. Zhao, Y. Zhao and N. Huang, "Covalent immobilization of phytic acid on $\mathrm{Mg}$ by alkaline pre-treatment: Corrosion and degradation behavior in phosphate buffered saline," Corros. Sci., 2013, 75, 280-286.

60. R.S. Stack, R.M. Califf, H.R. Phillips, D.B. Pryor, P.J. Quigley, R.P. Bauman, J.E. Tcheng and J.C. Greenfield, "Interventional cardiac-catheterization at DukeMedical-Center," Am. J. Cardiol., 1988, 62, F3-F24.

61. P. Barlis, J. Tanigawa and C. Di Mario, "Coronary bioabsorbable magnesium stent: 15month intravascular ultrasound and optical coherence tomography findings," Eur. Heart J., 2007, 28, no. 19, 2319. 
62. C.H. Ye, Y.F. Zheng, S.Q. Wang, T.F. Xi and Y.D. Li, "In vitro corrosion and biocompatibility study of phytic acid modified WE43 magnesium alloy," Appl. Surf. Sci., 2012, 258, 3420-3427.

63. L. Gao, C. Zhang, M. Zhang, X. Huang and X. Jiang, "Phytic acid conversion coating on Mg-Li alloy," J. Alloys Compd., 2009, 485, 789-793.

64. H.F. Gao, H.Q. Tan, J. Li, Y.Q. Wang and J.Q. Xun, "Synergistic effect of cerium conversion coating and phytic acid conversion coating on AZ31B magnesium alloy," Surf. Coat. Technol., 2012, 212, 32-36.

65. R.K. Gupta, K. Mensah-Darkwa, J. Sankar and D. Kumar, "Enhanced corrosion resistance of phytic acid coated magnesium by stearic acid treatment," Trans. Nonferrous Met. Soc. China, 2013, 23, 1237-1244.

66. R.F. Zhang, S.F. Zhang and S.W. Duo, "Influence of phytic acid concentration on coating properties obtained by MAO treatment on magnesium alloys," Appl. Surf. Sci., 2009, 255, 7893-7897.

67. F. Tang, X.Y. Wang, X.J. Xu and L.D. Li, "Phytic acid doped nanoparticles for green anticorrosion coatings," Colloids Surf., A, 2010, 369, 101-105.

68. X. Guo, K. Dua, Q. Guo, Y. Wang, R. Wang and F. Wang, "Effect of phytic acid on the corrosion inhibition of composite film coated on Mg-Gd-Y alloy," Corros. Sci., 2013, 76, 129-141.

69. G.M. Liu, L. Yang, F. Yu, J.H. Nian, S.W. Duo and N.Du, "Cerium-phytic acid passivation treatment on galvanized steel," Key Eng. Mater., 2008, 373-374, 228-231.

70. G.M. Liu, L. Yang and N. Du, "Study of molybdate-phytic acid passivating on galvanized steel," Corros. Eng., Sci. Technol., 2011, 46, no. 4, 542-546.

71. A.-R. El-Sayed, U. Harm, R.-M. Mangold and W. Furbeth, "Protection of galvanized steel from corrosion in $\mathrm{NaCl}$ solution by coverage with phytic acid SAM modified with same cations and thiols," Corros. Sci., 2012, 55, 339-350.

72. X. Gao, C. Zhao, H. Lu, F. Gao and H. Ma, "Influence of phytic acid on the corrosion behavior of iron under acidic and neutral conditions," Electrochim. Acta, 2014, 150, $188-196$.

73. R. Zhang, H. Yang, Y. Sun, W. Song, X. Zhu, N. Wang, Y. Wang, Y. Pan and Z. Zhang, "Competitive Adsorption of 4-Methyl-4H-1,2,4-triazole-3-thiol and Na Salt of Phytic Acid on a Silver Surface: Raman Spectral and Electrochemical Observations," J. Phys. Chem. C, 2009, 113, 9748-9754. 